\title{
Targeting Gai/s Proteins with Peptidyl Nucleotide Exchange Modulators
}

Britta Nubbemeyer, ${ }^{\text {a }}$ Ajay Abisheck Paul George,,${ }^{\text {ab }}$ Toni Kühl, ${ }^{\text {a }}$ Anna Pepanian, ${ }^{\text {a }}$ Maximilian Steve Beck, ${ }^{\mathrm{a}}$ Rahma Maghraby, ${ }^{a}$ Maryam Shetab Boushehri, ${ }^{\mathrm{c}}$ Maximilian Muehlhaupt, ${ }^{\mathrm{d}}$ Eva Marie Pfeil, ${ }^{\mathrm{e}}$ Suvi Katariina Annala, ${ }^{\mathrm{e}}$ Hermann Ammer, ${ }^{\mathrm{d}}$ Diana Imhof, ${ }^{\mathrm{a}^{*}}$ and Dehua Pei ${ }^{\mathrm{f}^{*}}$

aPharmaceutical Biochemistry and Bioanalytics, Pharmaceutical Institute, University of Bonn, An der Immenburg 4, 53121, Bonn, Germany. E-mail: dimhof@uni-bonn.de

bBioSolveIT GmbH, An der Ziegelei 79, 53757, Sankt Augustin, Germany.

'Pharmaceutical Technology and Biopharmacy, University of Bonn, Gerhard-Domagk-Str. 3, 53121, Bonn, Germany.

dInstitute of Pharmacology, Toxicology and Pharmacy, Veterinary Faculty, Ludwig Maximilian University of Munich, Königinstr. 16, 80539, Munich, Germany.

'Molecular, Cellular and Pharmacobiology Section, Institute of Pharmaceutical Biology, University of Bonn, Nussallee 6, 53115, Bonn, Germany.

fDepartment of Chemistry and Biochemistry, The Ohio State University, 578 Biosciences Building, $484 \mathrm{~W} 12^{\text {th }}$ Avenue, Columbus, OH 43210, USA, E-mail: pei@chemistry.ohio-state.edu 


\section{Table of Contents}

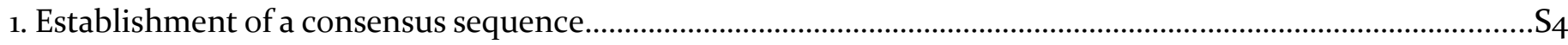

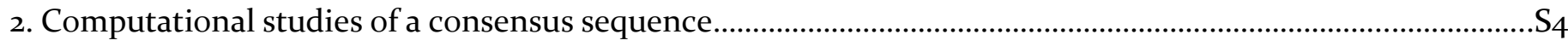

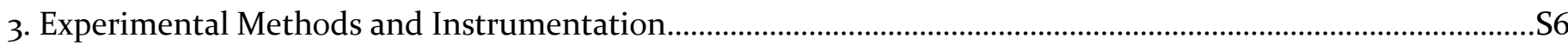

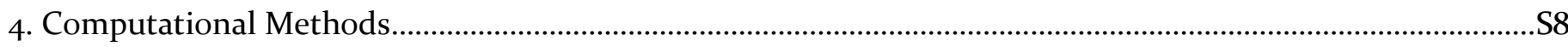

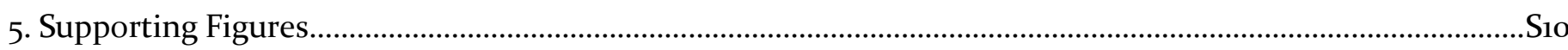

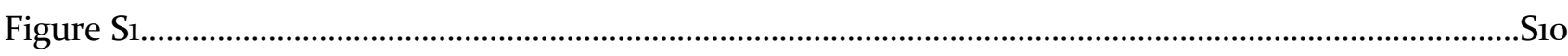

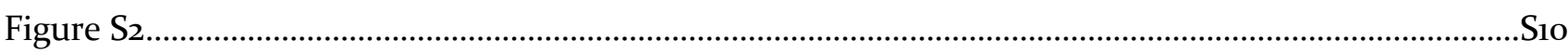

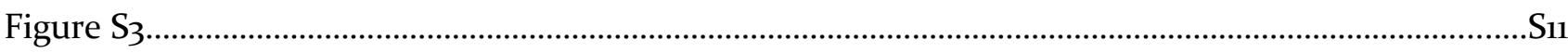

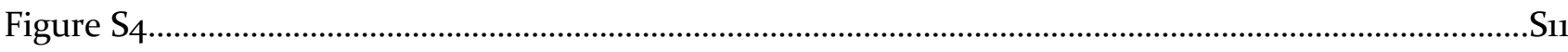

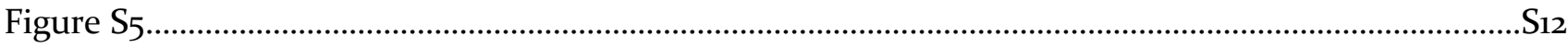

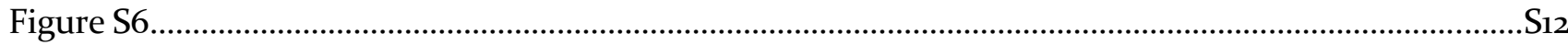

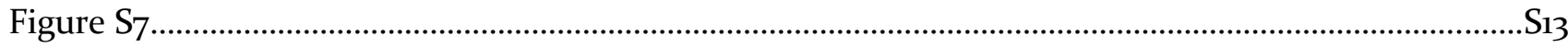

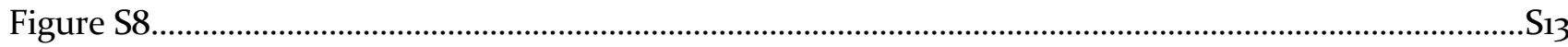

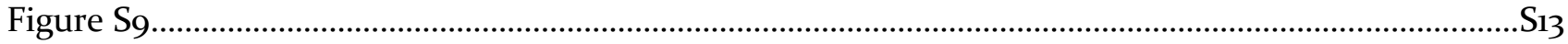

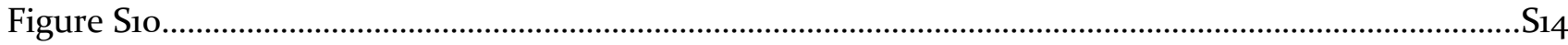

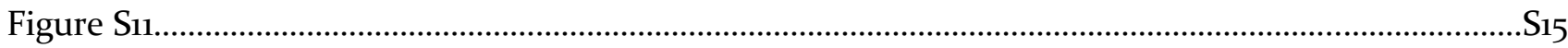

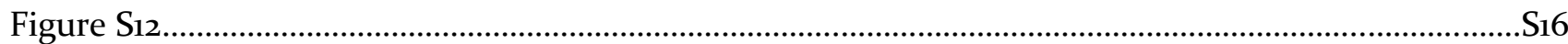

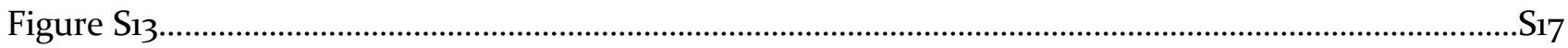

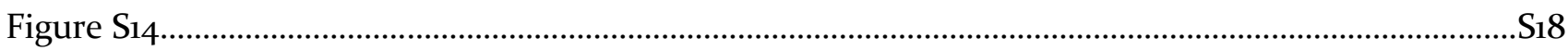

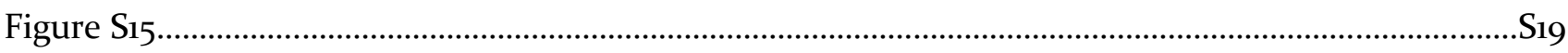

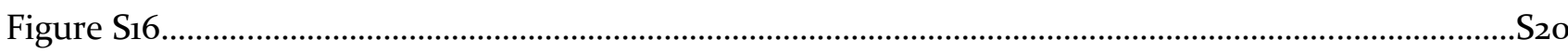

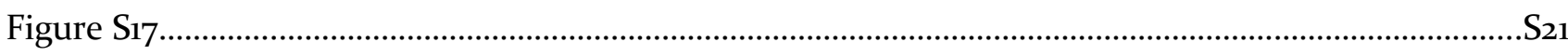

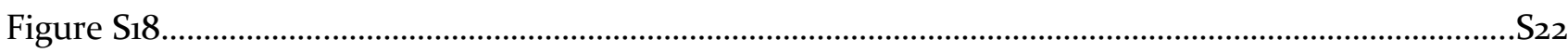

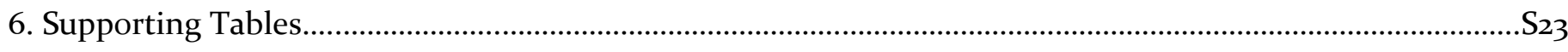

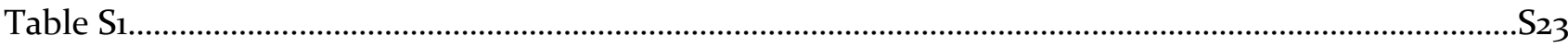

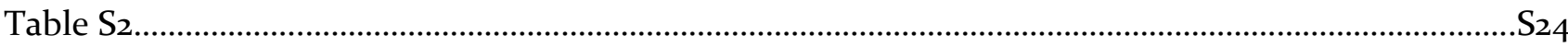

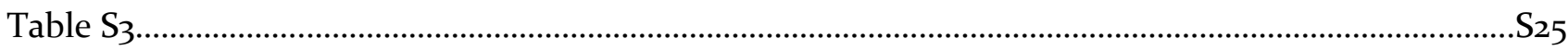

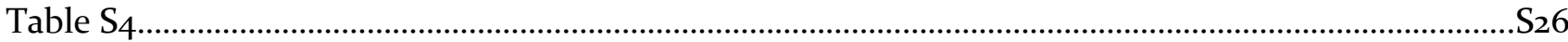

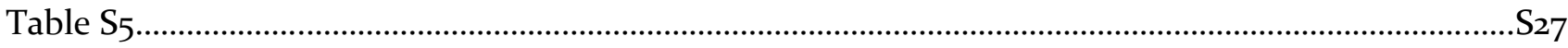

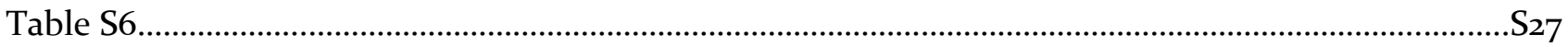

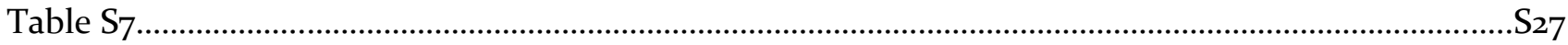

Table S8

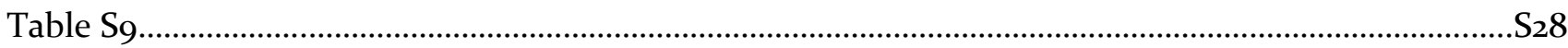

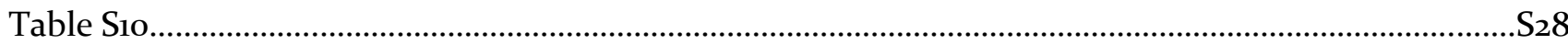

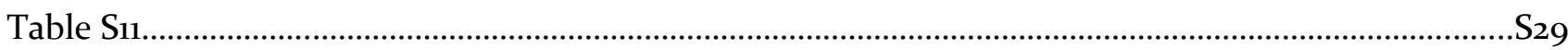


Table S12. S29

7. Supporting Video Description.. S30

Video S1 S30

Video S2. S30

Video S3. S30

8. References. $\mathrm{S}_{31}$ 


\section{Establishment of a consensus sequence}

From a library of $8.6 \cdot 10^{5}$ peptides, $\sim 600$ positive beads were collected by their turquoise color under a dissecting microscope. 101 hit sequences (Fig. S1, Table S1) were unambiguously identified by partial Edman degradation (PED)-MALDI-TOF-MS analysis and considered for further in-depth analysis., ${ }^{1,2}$ The examination of the hit sequences revealed, that basic $([+]: H, K, R)$ and large aromatic/hydrophobic amino acids $(\Omega: \mathrm{F}, \mathrm{W}, \mathrm{Y})$ occur more frequently at both $\mathrm{N}$ - and the C-terminal positions, whereas almost no acidic amino acids ([-]: D, E) were found (Fig. S1, Symbols according to Aasland et al.3). This is consistent with the previous observation that naturally occurring basic, hydrophobic peptides, such as melittin and mastoparan, act as Ga binders with a potential to influence the $G$ protein activity. 4,5

In the N-terminal positions $\mathrm{P}-4$ to $\mathrm{P}-1$, the basic amino acids Arg and Lys were more common, as were aromatic amino acids, i.e. Trp and Phe, at positions P-4 and P-3. This is in agreement with the established consensus sequence in Fig. Sic-d. In addition to the general trend of basic and hydrophobic amino acids, polar-neutral amino acids were also found in these positions as can be exemplified with Asn and Gln in P-4 as well as Ser, Thr and Tyr in P-1.

In the C-terminal positions, the basic amino acids, especially Arg, occurred in all positions most frequently. Additionally, the aromatic amino acids Tyr and Phe were commonly found in $\mathrm{P}+1$ to $\mathrm{P}+4$. Aliphatic amino acids $(\Psi$ : V, I, L, Nle) occurred in many cases in $\mathrm{P}+4$, while hydrophobic amino acids ( $\Phi$ : F, I, L, Nle, V, W, Y,) were often detected in P+1. In P+2 and P+3, it was more common that uncharged polar amino acids ( $\zeta$ : N, Q, S, T) occurred, in particular Tyr and Ser in P+2 and Gln and Asn in $\mathrm{P}+3 .{ }^{3}$

Overall, 13 representative peptides (1-13, Fig. 1) were selected for resynthesis and binding studies to verify the consensus sequence (Fig. 2c, S1, Tables S2, S3). Among the selected peptides, at least 6 out of 9 positions of the consensus sequence were covered by peptides 1 (GPM-1), 3, 8 and 9, whereas peptides 10 and $\mathbf{1 1}$ only matched the consensus sequence at $\mathbf{2}$ positions. However, the latter peptides were selected to cover a broad spectrum of the screening results.

\section{Computational studies to visualize peptide-Gai1/s interactions}

A homology model (Fig. S10, Tables $\mathrm{S}_{5}$, S6) of Gai1 was produced using an existing X-ray crystallographic structure (PDB: $3 \mathrm{UMS}^{6}$ ) and a first model of the NMR ensemble (PDB: ${ }_{5} \mathrm{JS}^{7}$ ) as templates in the YASARA molecular modeling suite (see Methods for details). The quality of the $3 \mathrm{D}$ model of Gai thus produced was deemed optimal with a YASARA Z-score of o.67, a Ramachandran Z-score of -0.65 and a DOPE score ${ }^{8}$ (a non-local normalized energy Z-score of -o.61 computed by the ANOLEA webserver ${ }^{9}$ (Table $S_{5}$ )). The model was subjected to a 500 ps refinement simulation ${ }^{10}$ using the YAMBER force field. The resulting lowest energy structure was used in all further analyses (Table S6). Similarly, 3D models of the peptides (GPM-1, GPM-1b-d, GPM-1 Y5A, and peptide 15) were also computationally generated (Fig. S15, Table $S_{7}$ ) in YASARA (see Methods for details), each of which was further subjected to a 100 ns, explicit, all-atom MD simulation using the AMBER14 force field ${ }^{11}$. Structural equilibration of the peptides was ascertained using the computed backbone RMSD (Tables S8-S10). The final structure from the equilibrated MD trajectory of each peptide was docked on the Gai structure via an "ensemble docking" approach ${ }^{12,13}$ implemented in YASARA using the VINA algorithm³ ${ }^{13}$ In addition, GPM-1, GPM-1 Y5A, GPM-1c and GPM-1d were docked similarly to a Gas crystal structure (PDB: 6EG8 ${ }^{14}$, chain I). Prior to molecular docking simulations, an exercise to

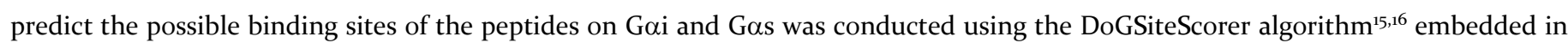
the molecular modeling suite SeeSAR (Fig. S12, S13, see Methods for details). Given the homology model of Gai with the GDP molecule removed as input, SeeSAR successfully predicted the GDP binding site on Gai as the primary binding site comprising of 35 residues and a second 21-residue binding site between the $\alpha_{2}$ and $\alpha_{3}$ helices on the model (Fig. S12). This predicted second binding site turned out to be the site Switch II/ $\alpha_{3}$ helix, where KB-752 and GIV also bound on Gai (Fig. S11), as well as the best binding for the peptides in this study as determined by independently conducted blind docking simulations (Fig. 4, S16). Additionally, a third smaller (15 residues) binding site was predicted by SeeSAR (Fig. S11). Interestingly, the C-terminal residues of GPM-1c (the best binding peptide) lodged into the grooves of this site, indicating that this prediction was not a trivial one. For Gas, the experimentally determined GDP binding site on Gas was correctly predicted, shown as binding site 1 (29 residues) in Fig. S13. The second predicted binding site (27 residues) largely overlaps with residues of binding site 1 and turned out to be the best binding site for the peptides used in this study. This indicates that 
peptide binding to binding site 2 will have a consequent effect on binding site 1 that houses the GDP molecule. A third binding site (17 residues) was also predicted to which only the peptide GPM-1 $\mathbf{Y}_{5} \mathbf{A}$ bound. As mentioned in the main text, since the experimental analysis could clearly classify the peptides into active (GPM-1C and GPM-1d), slightly active (GPM-1), and inactive (GPM-1b, GPM-1 $\mathrm{Y}_{5} \mathrm{~A}$ and 15), the extensive molecular docking and MD simulation of the docked complexes to determine relative binding energies were restricted to only these 6 peptides for Gai and to GPM-1, GPM-1c, GPM-1d and GPM-1 Y5A for Gas. The results of the docking exercise yielded in peptide-Gai/s complexes sorted by VINA-predicted binding affinities (Tables S8, S9, VINA's scoring function). The top two VINA-predicted peptide-Goi/s complexes for each peptide were further validated by the more rigorous binding affinity prediction protocol implemented by the PRODIGY server ${ }^{17}$, where it was confirmed that best binding energies predicted by VINA also had the best PRODIGY binding energy scores (Tables S8, S9). The complex with the best predicted binding for each peptide was further subjected to a $50 \mathrm{~ns}$, explicit-solvent, all-atom MD simulation. This step was undertaken in order to reproduce a physiological environment since complexes predicted via docking do not take solvent effects and the associated enthalpies and entropies into consideration. The peptideGai complexes are shown in Fig. 4 and Fig. S16, the peptide-Gas complexes are visualized in Fig. Si7.

The binding of GPM-1c to Gas involved multiple H-bonded contacts stabilizing the bound conformation (Fig. Sipb). It was observed that this stability was further enhanced by the fact that all residues with ring moieties (Phe1, Nal2, Trp9, Tyr12 and Tyr15) strongly blanketed the protein surface with hydrophobic interactions (Fig. S17a). The largest number of H-bonded partners on the protein (among all peptides analyzed), and the additional stability conferred by the hydrophobic interactions forms a clear basis for the high binding affinity of GPM-1c found by both experiments and computational investigations (Fig. 2c-d, Table S12). In the GPM-1d-Gas bound conformation, the residues Tyr5 and Tyr8 besides being stabilized by H-bonded interactions with the Gas residues are involved in hydrophobic interactions with the protein surface which contributes to their stability and also to longer residence times of the aforementioned H-bonded interactions (Fig. S17e-f). Additional hydrophobic interactions between the rings systems of Phe11 and Nalı2 stabilize the binding. The locked conformation induced by the cyclic moiety further orients Trp2 of GPM-1d to participate in hydrophobic interactions with the protein, further stabilizing the binding. In GPM-1, the residues Tyr5 and Tyr8 are involved in hydrophobic interactions with the protein surface, which in turn contribute to their orientations favorable for persistent $\mathrm{H}$-bonds as shown in Fig. S17c-d. Trp2 stays buried in a deep hydrophobic groove formed between the Switch II and $\alpha_{3}$ structural elements. In the case of GPM-1 Y 5A, the initial bound conformation is stabilized by hydrophobic interactions between the residues Trp2 and Tyr8 of the peptide and the protein. However, the peptide is unstable in this conformation and quickly dissociates into bulk solution only to be held by long range electrostatic forces (Fig. S17g). Similar to the Gai-GPM-1 interaction, the Tyr5 residue appears to be crucial for the Gas interaction as well, since the mutant does not form a stable complex. A loss of binding affinity and activity of the KB-752 Phe8Ala mutant towards Gas was also described, which is another indication of the KB-752-like mode of action of GPM-1. ${ }^{18}$ As opposed to peptide-Gai interactions, peptide-Gas interactions had a proportional increase of GDP binding to Gas as shown in Table S12 and Fig. S18. Our results thereby indicate that the active and slightly active peptides investigated in this study (GPM-1c, GPM-1d, and GPM-1) act as effective GDIs on Gas. 


\section{Experimental Methods and Instrumentation}

General chemicals and stock solutions. All reagents were purchased from commercial sources and were used without further purification. Standard coupling reagents, resins and amino acid derivatives used for solid phase synthesis were obtained from Orpegen Peptide Chemicals GmbH, Novabiochem and IRIS Biotech. Peptide synthesis reagents and solvents were of reagent grade, and solvents for chromatography were of analytical grade obtained from VWR International. Oxygen- or water-sensitive reactions were performed under argon atmosphere. Guanine nucleotides for membrane assays and tissue culture reagents were from Calbiochem and Thermo Fisher Scientific. All other reagents were from Sigma-Aldrich unless stated otherwise.

\section{Binding studies}

For the binding studies, $\mathrm{G} \alpha$ protein previously stored at $-80{ }^{\circ} \mathrm{C}$ was rebuffered on a PD-10 column (SephadexTM G-25 M with o.1\% Kathon ${ }^{\mathrm{TM}}$ CG, GE Healthcare) and concentrated with an Amicon Ultra-3oK (Merck Millipore Ltd.) filter. The final protein concentration was determined by Bradford assay as described above. ${ }^{19}$

The microscale thermophoresis (MST) measurements were performed with Monolith NT115 instruments from NanoTemper Technologies $\mathrm{GmbH}$. For the G $\alpha$ protein, different concentrations varying from $0.5 \mathrm{nM}-40,000 \mathrm{nM}$ were prepared by serial dilution in buffer (20 mM HEPES, $100 \mathrm{mM} \mathrm{NaCl}, 2 \mathrm{mM} \mathrm{DTT,} 1 \mathrm{mM} \mathrm{MgCl}$, $\mathrm{pH}$ 8.0) containing 5\% (v/v) DMSO and 0.05\% (v/v) Tween2o. The fluorescence-labeled peptides were dissolved in DMSO (5\% (v/v) DMSO final) and diluted to a final concentration of $100 \mathrm{nM}$ in the same buffer. Then, the peptide solution was diluted 1:1 with the Ga protein and incubated at room temperature for 30 min. In addition, a control without $\mathrm{G} \alpha$ protein was prepared. For the MST measurement, the solution was transferred into Monolith NT115 standard treated glass capillaries from NanoTemper. The thermophoresis was measured twice for each capillary at 50\% LED power and $40 \%$ MST power. The baseline corrected data were normalized to the curve amplitude and analyzed with Graph Pad Prism 7.o by using the following equation provided by NanoTemper (1).

(1) $f(c)=$ unbound $+($ bound - unbound $) \cdot\left(c+c_{\text {target }}+K_{d}-\sqrt{\left(c+c_{\text {target }}+K_{d}\right)^{2}-4 \cdot c \cdot c_{\text {target }}}\right) /\left(2 \cdot c_{\text {target }}\right)$

For the competition experiment, $200 \mathrm{nM} \mathrm{Cf-KB-752} \mathrm{and} 200 \mathrm{nM} \mathrm{G \alpha i \cdot GDP}$ were mixed in a 1:1 (v/v) ratio and incubated for 15 min at room temperature. Subsequently, GPM-1 was added in concentrations ranging from 1.22-10,0oo nM. The solution (50 nM Cf-KB-752, 50 nM Gai-GDP, varying concentration of GPM-1) was transferred into the capillaries and the MST measurement was initiated immediately. As a control, a measurement without the addition of GPM-1 was performed. The values obtained were normalized to the maximal deviation: complete complexation of Cf-KB-752 and Gail minus the maximum displacement caused by the highest GPM-1 concentration. The $\mathrm{IC}_{50}$ value was calculated by a one-site fit $\log \mathrm{IC}_{50}$ model (equation (2)) using GraphPad Prism 7.o.

(2) $Y=$ Bottom $+($ Top - Bottom $) /\left(1+10^{\left(X-\log \left(I C_{50}\right)\right.}\right)$

Surface plasmon resonance (SPR) measurements were conducted on a Biacore $8 \mathrm{~K}$ device from GE Healthcare. All experiments were carried out at $25^{\circ} \mathrm{C}$ in SPR buffer (10 mM HEPES, $150 \mathrm{mM} \mathrm{NaCl}, 1 \mathrm{mM} \mathrm{MgCl} 2,0.05 \%$ (v/v) Tween2o, $\mathrm{pH}$ 7.4). A streptavidin-coated sensor chip (Series S, Sensor Chip SA, GE Healthcare) was conditioned with $1 \mathrm{M} \mathrm{NaCl} / 50 \mathrm{mM} \mathrm{NaOH}$ according to the manufacturer's instructions. The biotinylated peptides (Btn-GPM-1, Btn-GPM-1c, Btn-GPM-1d and Btn-15) were immobilized on the sensor chip at a flow rate of $10 \mu \mathrm{min}^{-1}$ for 1 min to reach an increase of 6oo response units for Btn-GPM-1 and Btn-15 and 1200 response units for BtnGPM-1c and Btn-GPM-1d. A blank flow cell was used as a control for correction of nonspecific binding as described previously.20

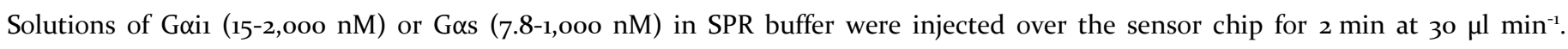
Dissociation was monitored for $400 \mathrm{~s}$ applying SPR buffer. The chip surface was regenerated with $200 \mathrm{mM} \mathrm{NaCl}$ containing $10 \mathrm{mM}$ $\mathrm{NaOH}$ for $15 \mathrm{~s}$ at $30 \mu \mathrm{min}^{-1}$ for three times. Data evaluation was carried out with the Biacore ${ }^{\mathrm{TM}}$ Insight Evaluation Software and

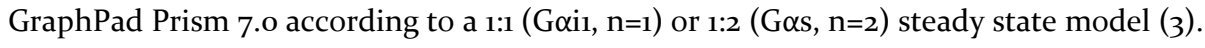


(3) $Y=R U_{\max } \cdot X^{\left(n /\left(K_{d}^{n}+X^{n}\right)\right)}$

\section{Cell-free ELISA-based assay}

The functional activity of the test compounds on intact inhibitory and stimulatory signal transduction pathways was investigated in a cell-free system using membranes from Neuroblastoma×glioma (NG108-15 cells) hybrid cells (endogenous $\delta$-opioid receptors; o.67 pmol $\mathrm{mg}^{-1}$ membrane protein) stably transfected to express the human $\beta 2$-adrenoceptor (1.03 $\mathrm{pmol} \mathrm{mg}^{-1} \mathrm{membrane}$ protein). ${ }^{21}$ Cells were cultured in Dulbecco's modified Eagle's medium (DMEM) supplemented with $5 \%$ (v/v) foetal bovine serum, $100 \mu \mathrm{M}$ hypoxanthine, 1 $\mu \mathrm{M}$ aminopterin, $16 \mu \mathrm{M}$ thymidine, 100 units $\mathrm{ml}^{-1}$ penicillin, and $100 \mu \mathrm{g} \mathrm{ml}{ }^{-1}$ streptomycin at $37^{\circ} \mathrm{C}_{\text {in }}$ a humidified atmosphere of $5 \% \mathrm{CO}_{2}$ in air. Subconfluent monolayers (70\% density) were harvested, membranes were prepared as described ${ }^{22}$ and stored in aliquots in NMT buffer (20 mM Tris. $\mathrm{HCl}, \mathrm{pH} 7.4$, containing $150 \mathrm{mM} \mathrm{NaCl}$ and $10 \mathrm{mM} \mathrm{MgCl}$ ) at a concentration of $2 \mathrm{mg} \mathrm{ml}^{-1}$ protein at $-80{ }^{\circ} \mathrm{C}$. For screening of the $G$ protein modulators, membranes were thawed and preincubated with the respective peptides for 30 min on ice. Therefore, the peptides were dissolved in DMSO to a final concentration of $200 \mu \mathrm{M}$ (stem solution). Subsequently, each incubation experiment contained $300 \mu \mathrm{g}$ of membrane protein and $50 \mu \mathrm{M}$ peptide in a total volume of $300 \mu \mathrm{l}$ of NMT buffer, which corresponds to $25 \%(\mathrm{v} / \mathrm{v})$ of DMSO. Adenylyl cyclase reactions were started by the addition of $20 \mu \mathrm{l}$ of preincubated membranes to an assay system (100 $\mu$ l total volume) containing (final concentrations for all components are given) $40 \mathrm{mM}$ Tris·HCl, $\mathrm{pH}$ 7.4, o.2 mM EGTA, o.2 mM DTT, $100 \mathrm{mM} \mathrm{NaCl}, 10 \mathrm{mM} \mathrm{MgCl}_{2}, 0.5 \mathrm{mM} \mathrm{ATP}_{5} \mu \mathrm{g} \mathrm{ml}^{-1}$ phosphocreatine, $5 \mathrm{IU} \mathrm{ml}^{-1}$ creatine phosphokinase, $10 \mu \mathrm{M}$ GTP, $10 \mu \mathrm{M}$ IBMX (3-isobutyl-1-methylxan-thine), $5 \%$ (v/v) DMSO and $10 \mu \mathrm{M}$ of the peptides. The mixture was kept at $37{ }^{\circ} \mathrm{C}$ for 10 min and stopped by the addition of ice-cold $10 \mathrm{mM} \mathrm{HCl}(500 \mu \mathrm{l})$. Adenylyl cyclase activity was determined in the absence (basal) or presence of forskolin, isoproterenol and DADLE (10 $\mu \mathrm{M}$ each) in order to assess the effect of test compounds on direct or receptor-mediated stimulation and inhibition of adenylyl cyclase, respectively. ${ }^{22}$ The amount of cAMP generated was determined by a generic cAMP ELISA after acetylation of the samples. ${ }^{23}$ CAMP levels were normalized to forskolin-stimulated cAMP values in control experiments using the solvent DMSO alone and evaluated using GraphPad Prism 7.o.

\section{Whole cell HTRF-based assay}

HEK293 cells were obtained from the American Type Culture Collection (ATCC) and maintained in humidified atmosphere at $37^{\circ} \mathrm{C}$ and $5 \% \mathrm{CO}_{2}$. The HEK293 cells were cultured in DMEM and were tested negative by PCR for mycoplasma contamination. The homogeneous time-resolved fluorescence (HTRF)-based assay was carried out according to manufacturer's instructions (Cisbio GmbH) as described previously. ${ }^{24-26}$ In brief, 500 cells/well were suspended in assay buffer containing $1 \mathrm{mM}$ IBMX and incubated in a 384-well, white microtiter plate for $15 \mathrm{~min}$. To determine inhibitory effects of the compounds, cells were preincubated with ligands (dissolved in DMSO, final DMSO concentration: $0.05 \%(\mathrm{v} / \mathrm{v}))$ or solvent for $2 \mathrm{~h}$ prior to stimulation with $100 \mu \mathrm{M}$ Iper-6-phth ${ }^{27,28}$ for further $30-35$ min. Reactions were terminated by addition of lysis buffer containing the $\mathrm{HTRF}^{\circledR}$ reagents. All incubation steps were carried out at $37^{\circ} \mathrm{C}$ and $5 \% \mathrm{CO}_{2}$. After incubation for at least $\mathrm{i}$ h at room temperature, HTRF ratios were measured using the Mithras LB 940 multimode reader (Berthold technologies) at $665 \mathrm{~nm}$ and $620 \mathrm{~nm}$, then converted to $\mathrm{nM}$ values according to the manufacturer's instructions and normalized to the isoproterenol signal. ${ }^{24}$

\section{MTT-assay}

HEK 293 cells were purchased from Sigma-Aldrich. The cells were maintained in DMEM supplemented with $10 \% \mathrm{FBS}^{\circ}, \mathrm{Hg}^{-1}$ streptomycin and $50 \mathrm{U} \mathrm{ml}^{-1}$ penicillin, and were cultivated in a $37{ }^{\circ} \mathrm{C}$ incubator with $5 \% \mathrm{CO}_{2}$ and $95 \%$ humidified air. The toxicity of the peptides for the cells was determined using the MTT assay. Briefly, the cells were seeded in 96-well culture dishes with a density of 2.5 $10^{4}$ cells per well. Following adherence, the cells were incubated overnight with various concentrations of different peptides. The

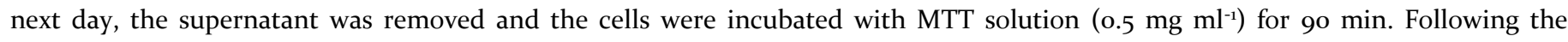
aspiration of the supernatant, the MTT crystals were dissolved in MTT, and the absorbance was measured at 540 nm. Survival was expressed as percent relative to the untreated control. 


\section{Computational Methods}

\section{Molecular modeling of peptide structures}

Owing to the lack of experimentally resolved 3 D structures for the peptides (GPM-1, GPM-1b-d, GPM-1 Y5A, and 15) a computational modeling approach was pursued (Fig. S15). The YASARA (version 19.7.17) 29,30 $^{20}$ modeling suite was used as the primary tool in this effort. As the first step, peptide sequences in the FASTA format were loaded into YASARA. At this point the non-standard amino acid residues (L-2-naphthylalanine (2Nal), (S)-2,3-diaminopropionic acid (Dap) and isophthalic acid (Ipa)) in the peptides were substituted by standard amino acid residue placeholders before they were manually changed to their desired structures as follows. The 2 Nal residues in GPM-1c, GPM-1d, and $\mathbf{1 5}$ as well as Ipa in GPM-1d were initially loaded as phenylalanine residues in the FASTA format before the appropriate structural changes were manually introduced. Similarly, a serine residue served as initial placeholder for Dap in GPM-1d. Amide C-terminal caps were added to all peptides as part of the initial structural assembly. The appropriate peptide cyclization steps were also done manually in YASARA (for GPM-1b and GPM-1d) on the linear structures. At this stage most peptides sported bonds with unnatural lengths and were therefore subject to an energy minimization. Herein a protocol combining steepest descents and simulated annealing as implemented by YASARA was used with Amber ffi4SB ${ }^{11}$ as the force field. Force field parameters for all nonnatural amino acids were derived using the AutoSMILES (http://www.yasara.org/autosmiles.htm) method implemented in YASARA. The method uses the AM1-BCC ${ }^{31}$ model to compute atomic partial charges and the General Amber Force Field (GAFF) ${ }^{32}$ to determine the remaining force field terms. The energy-minimized peptide structures thus built were used as starting coordinates in all further computational analyses in the current study. Analysis and energy minimizations were performed using the YASARA molecular modeling software (YASARA structure, Version 20.4.24, YASARA Biosciences GmbH). The YASARAz force field was used for energy minimization by simulated annealing, including the optimization of the hydrogen bond network and the equilibration of the water shell, until system convergence was achieved. The molecular graphics were created using YASARA (YASARA structure, Version 20.4.24, YASARA Biosciences GmbH, www.yasara.org) and POVRay (Persistence of Vision Raytracer Pty. Ltd., www.povray.org).

\section{Homology modeling}

A homology model of Gai, used as the target structure in all molecular docking simulations in this study was produced using the protocol available in YASARA (Version 20.4.24). The target sequence along with explicitly defined template structures namely PDB: ${ }_{3} \mathrm{UMS}^{6}$, PDB: $5 \mathrm{JS}^{7}$ and PDB: ${ }_{1} \mathrm{Y}_{3} \mathrm{~A}^{33}$ fed in as inputs to the program. The individual steps that were automatically performed by the program without further user intervention as described earlier. 33

\section{Molecular docking studies}

Based on experimental consensus, blind docking simulations were conducted wherein the resultant structures from the MD simulations

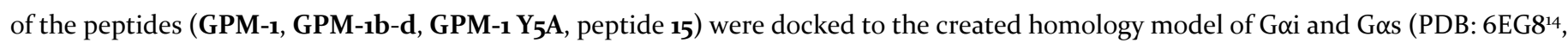
chain I). Blind docking protocols are usually used to scan for possible binding sites and binding modes of peptide ligands over the surface of the target proteins. Following an "ensemble docking" protocol ${ }^{12,13}$, the best docked poses of peptides-protein complexes based on the predicted binding energies were chosen and analyzed. "Ensemble docking" as implemented in YASARA produces an ensemble of multiple receptor conformations by generating multiple side-chain rotamers on a fixed backbone. This method has been successfully employed in previous studies involving peptide docking. ${ }^{34}$

\section{Molecular dynamics simulations}

Molecular dynamics (MD) simulations were carried out to accomplish two main tasks. First, 10o ns MD simulations were run to generate a 3 D conformational ensemble for the peptides (GPM-1, GPM-1b-d, GPM-1 Y5A, peptide 15). Next, 50 ns refine, equilibrate, and obtain binding energy estimates from the Gai-peptide and Gas-peptide (GPM-1b and peptide 15 not conducted) complexes obtained from molecular docking experiments. The simulations were conducted using the standard protocol (md_run.mcr) available in YASARA, using the Amber ffi $4 \mathrm{SB}^{11}$ force field. As explained earlier, force field parameters for the non-canonical amino acids in the peptides were derived on-the-fly using the AutoSMILES method implemented in YASARA. The rest of the setup for the simulations were maintained identical

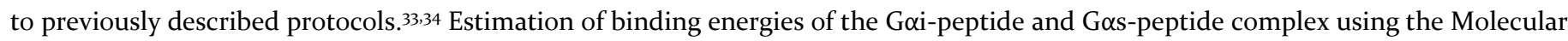


Mechanics Poisson-Boltzmann Surface Area (MMPBSA) method as implemented in YASARA was done identical to previous instances. ${ }^{34,35}$

\section{Analysis of molecular simulation data}

MD trajectories produced by YASARA were converted to the PDB format and imported into VMD (version 1.9.3) for analysis of the evolution of structural and energetic properties. SeeSAR 10.1 (BioSolveIT GmbH, 2020, www.biosolveit.de/SeeSAR) was used to analyze the atomic contributions to the binding energies of selected Gai·GDP and Gas.GDP simulation snapshots, using the HYDE scoring function ${ }^{36}$ implemented in the program. Furthermore, the depiction of HYDE coronas on different bound conformations of the GDP molecules from different simulation snapshots served as a fast and visual means to understand the atomic contributions to the affinity in each case. SeeSAR was also used in the independent identification and validation of the potential binding sites for the peptides on Gai using the DoGSiteScorer algorithm¹5. Molecular graphics were generated using VMD, SeeSAR and YASARA.

\section{Accession codes}

All structures used for the computational analyses in the current articles are deposited in the PDB under the accession codes 5JS8, $3 \mathrm{UMS}, \mathrm{Y}_{3} \mathrm{~A}$, and $6 \mathrm{EG} 8$. 


\section{Supporting Figures}
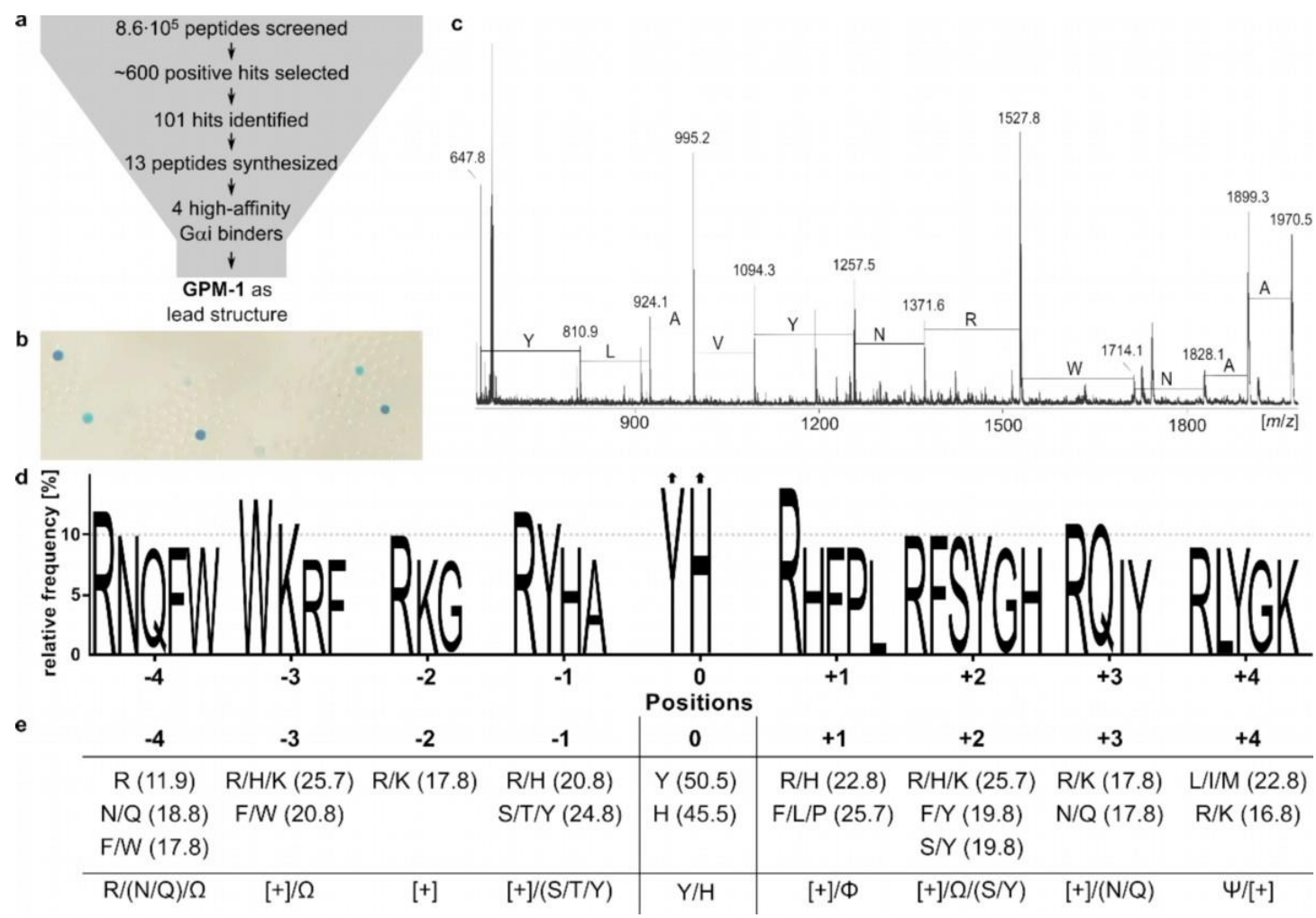

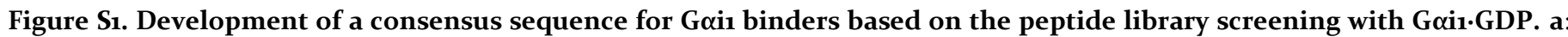
Schematic representation of the hit identification and selection. $\mathbf{b}$ : Identification of Gair.GDP binders after incubation with o.1 nM protein for $1 \mathrm{~h}$ and subsequent detection by incubation with BCIP-substrate (5-bromo-4-chloro-3-indolylphosphate) and dye precipitation. ${ }^{1} \mathbf{c}$ : Example of a representative PED-MALDI-MS spectrum of a hit sequence, i.e. NWRNYVALY. d: Relative frequency of amino acids $(\geq 8 \%)$ at positions $\mathrm{P}-4$ to $\mathrm{P}+4$ relative to position o $\left(\mathrm{Po}, \mathrm{C} / \mathrm{H} / \mathrm{Y},{ }^{37}\right)$. e: Amino acid preferences at the different positions are given relative to Po. The postulated consensus sequence is written in the one-letter code and according to Aasland et al. ${ }^{3}$ as follows: $\Phi$ :

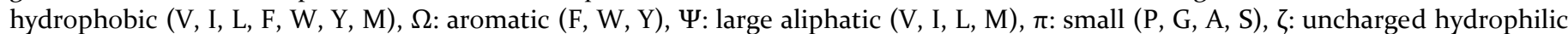
$(\mathrm{N}, \mathrm{Q}, \mathrm{S}, \mathrm{T}),[+]$ : basic $(\mathrm{H}, \mathrm{K}, \mathrm{R})$ and [-]: acidic (D, E) amino acids; $\mathrm{M}=$ norleucine (Nle) ${ }^{37}$.

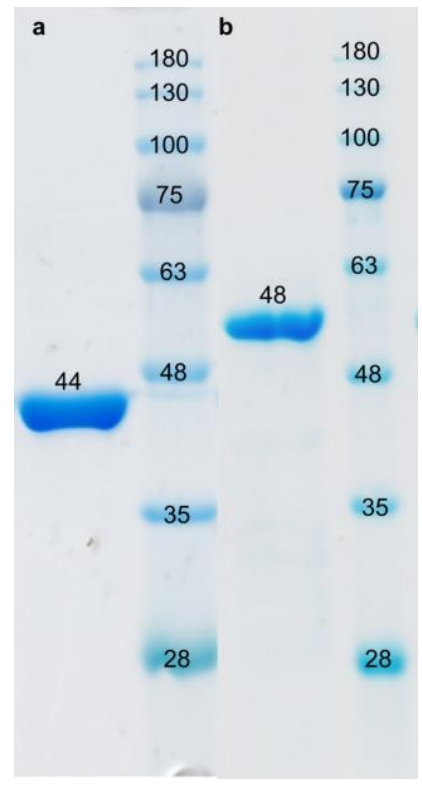

Figure S2. SDS-PAGE analysis of recombinantly expressed and purified Gai (a) and Gas (b) proteins. The His-tagged proteins were transformed in E. coli BL21 (DE3) cells. 

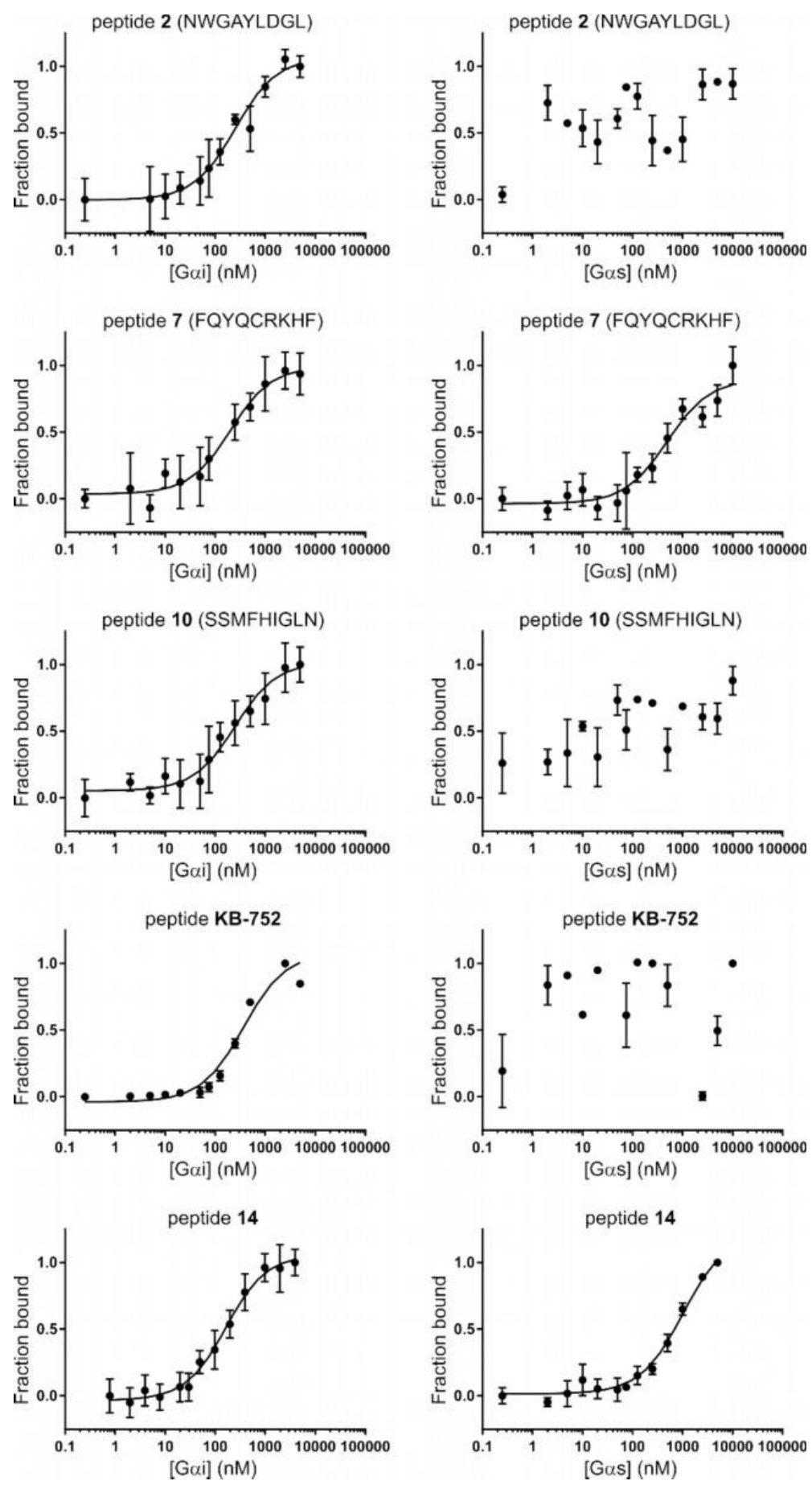

Figure $S_{3}$. Binding curves obtained from the MST experiment. Binding curves of $50 \mathrm{nM} 5(6)$-carboxyfluorescein-labeled peptides

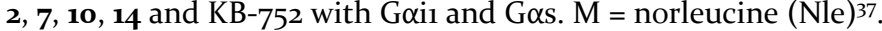

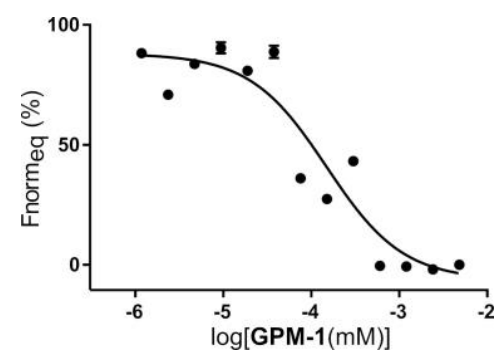

Figure $S_{4}$. Competition assays of peptide 1 (GPM-1) and Cf-KB-752. After preincubation of 5(6)-carboxyfluorescein-labeled KB-752 (final $50 \mathrm{nM}$ ) and Gair (final $50 \mathrm{nM}$ ) various GPM-1 concentrations (o.61-500o nM) were added and the changes in the thermophoretic effects were measured. 

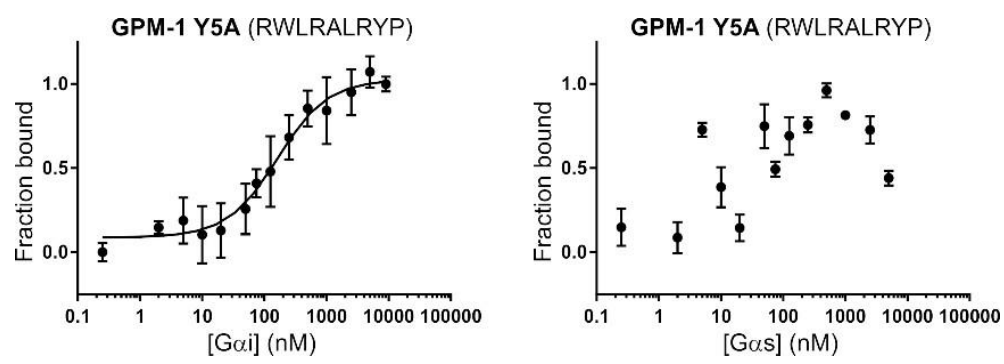

Figure S5. Binding curves obtained from the MST experiment. The binding of 50 nM 5(6)-carboxyfluorescein-labeled GPM-1 Y5A

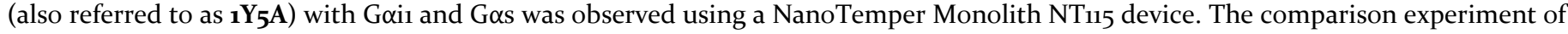
GPM-1 (peptide 1) and GPM-1 Y5A with Gail.GDP showed that the $K_{\mathrm{d}}$ value of the GPM-1 $\mathbf{Y}_{\mathbf{5}} \mathbf{A}$ mutant was approximately two times higher than that of GPM-1. In the experiment with Gas.GDP, no binding was obtained for the GPM-1 Y5A mutant.

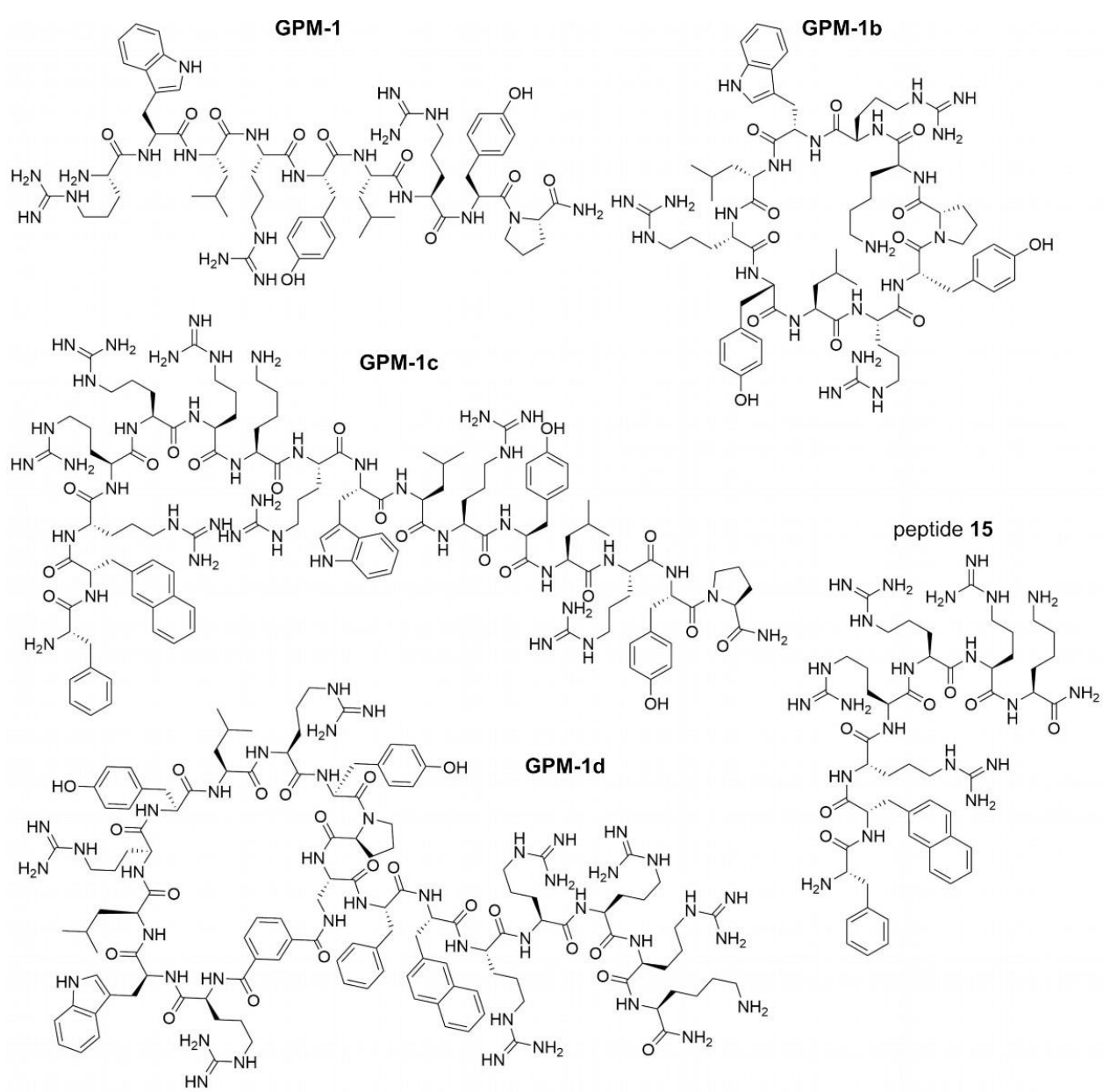

Figure S6. 2D structures of GPM-1, 15 and the GPM-1-derived peptides GPM-1b, GPM-1c and GPM-1d. The 2D structures were drawn with ChemDraw Prime 16.o. 

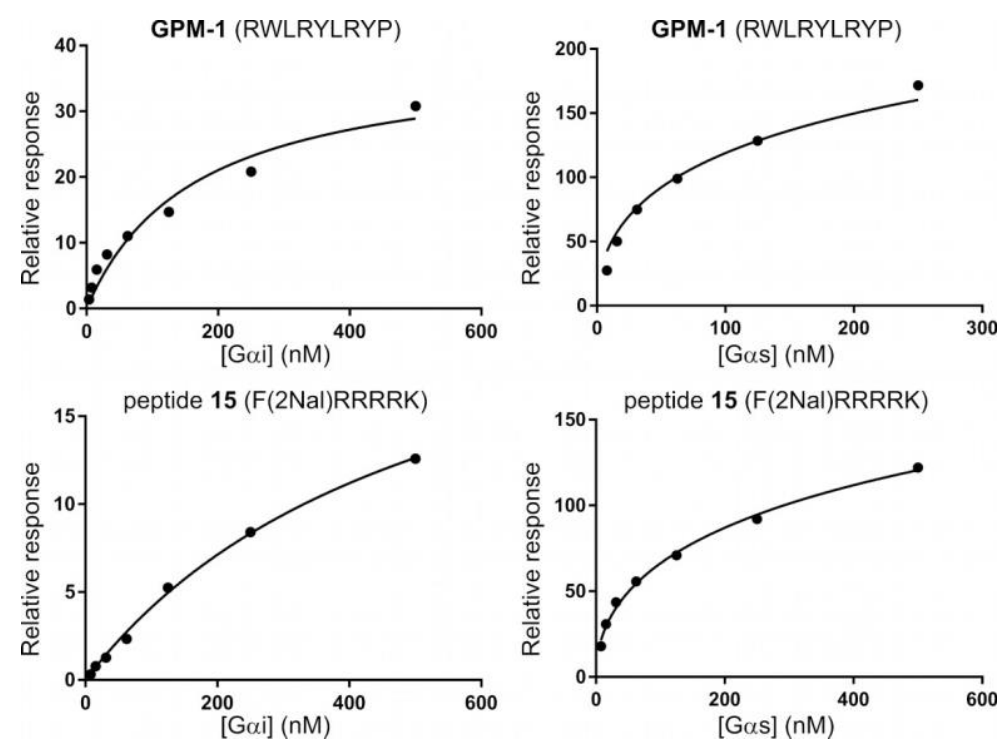

Figure S7. Binding curves obtained from the SPR experiment. Binding curves of immobilized biotinylated GPM-1 and peptide 15 with Gair and Gas.

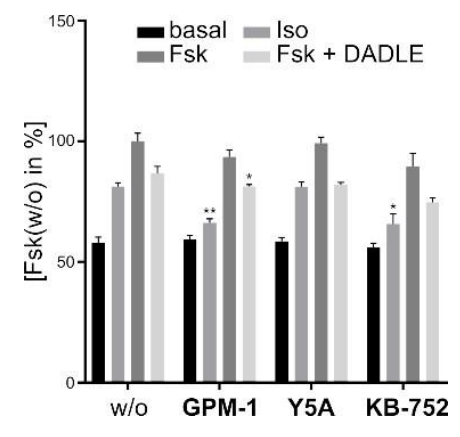

Figure S8. Relative cAMP levels on differently induced NG108-15 membrane preparations incubated with or without potential G protein modulators (GPM-1, GPM-1 Y $\mathbf{5 A}$ and KB-752) in the presence of a phosphodiesterase inhibitor. cAMP levels were normalized to Fsk of w/o. Shown are percentage values of membranes incubated in the absence (basal), or in the presence of Iso, Fsk and Fsk+DADLE. Error bars represent $\mathrm{SD}$ for $\mathrm{n}=3$. Statistical analysis was performed using the One-Way ANOVA Test Dunnet corrected, with ${ }^{*} \mathrm{p}<0.05,{ }^{* *} \mathrm{p}<0.01$, and ${ }^{* * *} \mathrm{p}<0.0001$ for comparisons with the control (w/o).

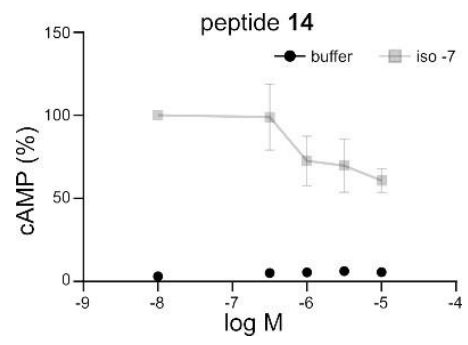

Figure S9. Iso-induced cAMP accumulation in HEK293 cells. Depicted are the buffer controls (black) and the Iso values (grey) for peptide $\mathbf{1 4}$ in \% cAMP. Error bars represent SD for $\mathrm{n}=3$. 


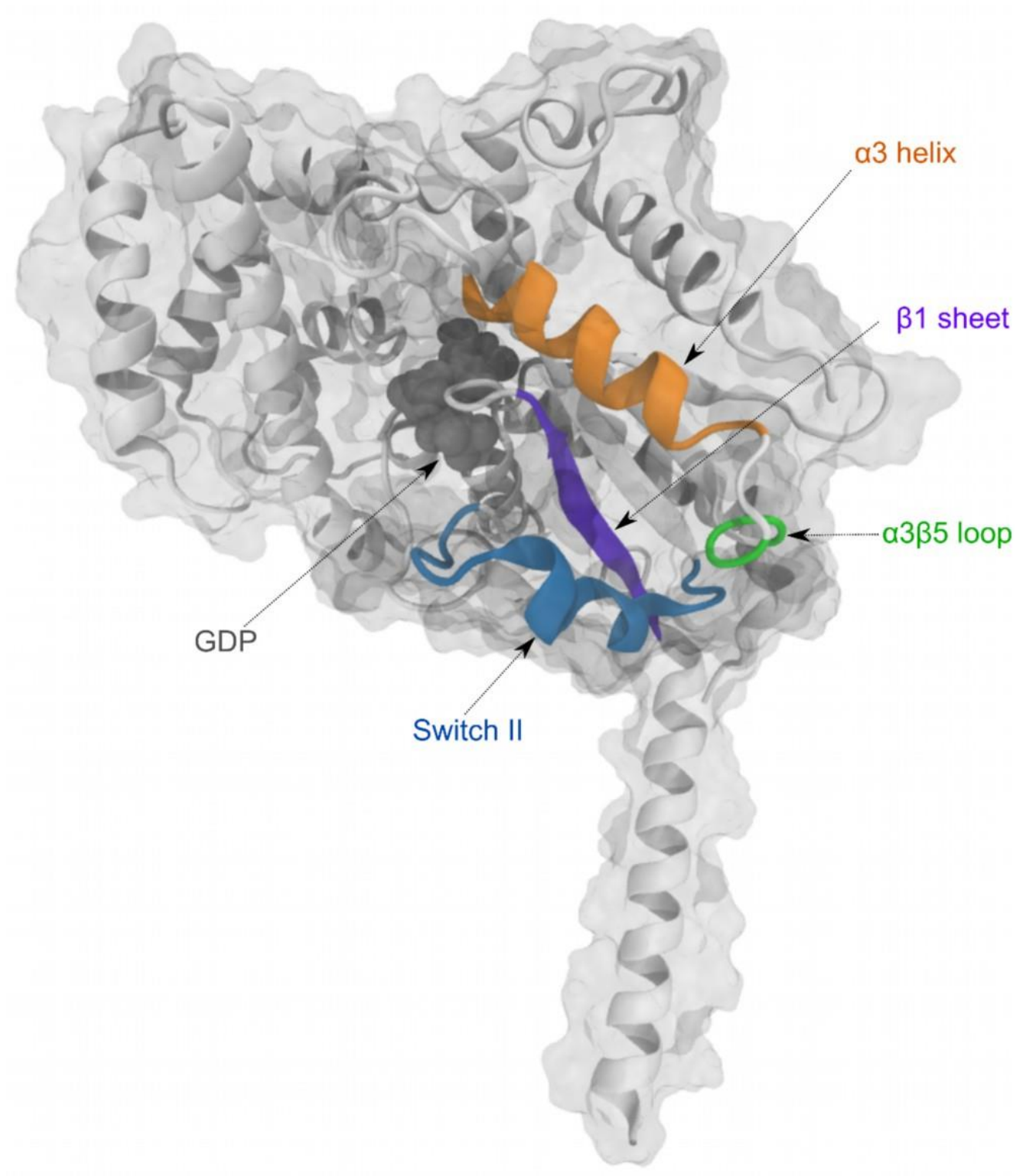

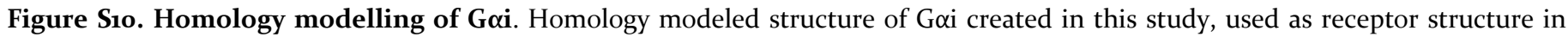
subsequent docking, and molecular dynamics simulations. The structure is depicted as white ribbons with its molecular surface representation overlaid. The segments Switch II (blue), $\alpha_{3}$ (orange), $\beta_{1}$ (cyan), and the $\alpha_{3}-\beta_{5}$ loop (green) that house the known inhibitor KB-752 are distinctly highlighted and the bound GDP molecule is shown in its VdW surface representation colored gray. 


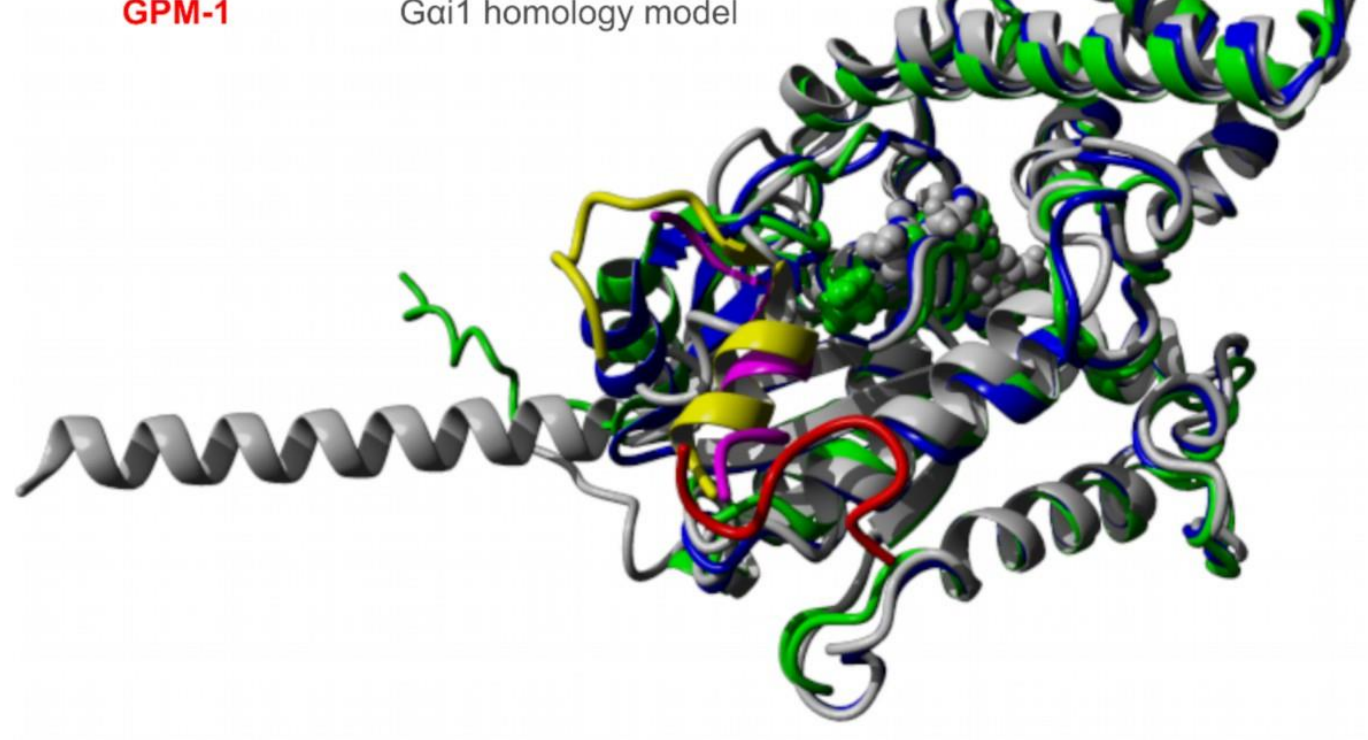

Figure S11. The Fig. shows the structural alignment between two X-ray crystallographic structures of Gai namely, (chain B of) PDB ${ }_{1} \mathrm{Y}_{3} \mathrm{~A}^{33}$ (blue cartoon) bound to the GDP-selective peptide KB-752 (pink cartoon), PDB 6MHF40 (green cartoon), bound to the GDPselective GEM-peptide derived from GIV (yellow cartoon), and the homology model of Gai (gray cartoon and molecular surface) created in this study with the molecular docking-generated bound conformation of GPM-1 (red cartoon). The backbone alignment between three structures had an RMSD of 1.63 Å over 285 aligned residues with $99.30 \%$ sequence identity. The overlapping positioning of the bound conformations of KB-752 (pink cartoon), GIV (yellow cartoon), and GPM-1 (red cartoon) indicate that all three peptides bind to a very similar region on Gai. 
a

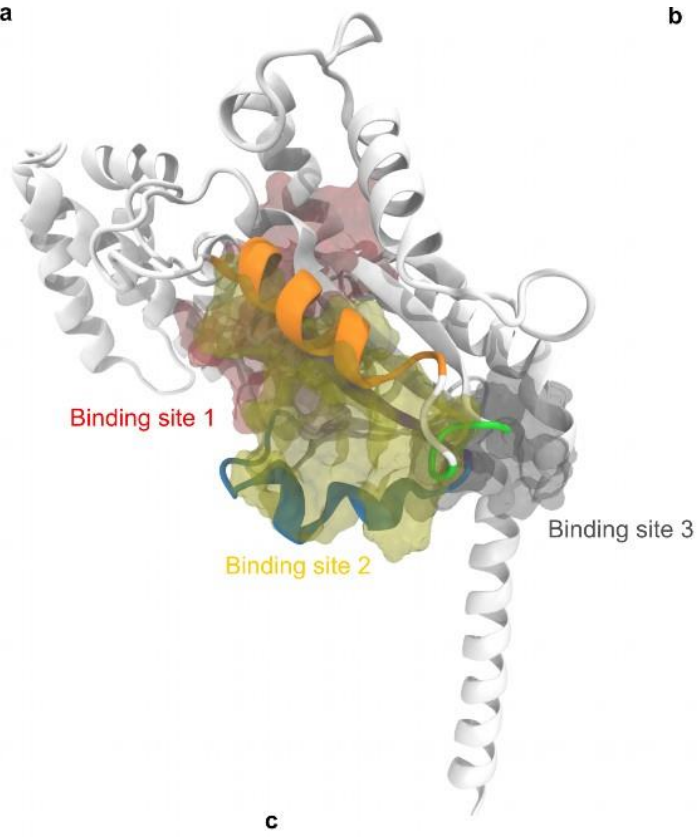

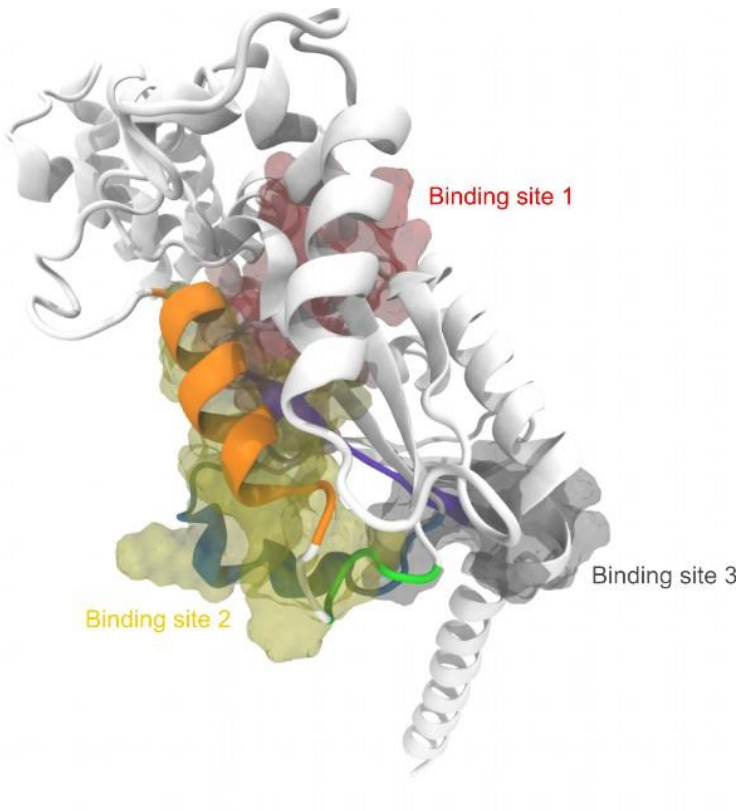

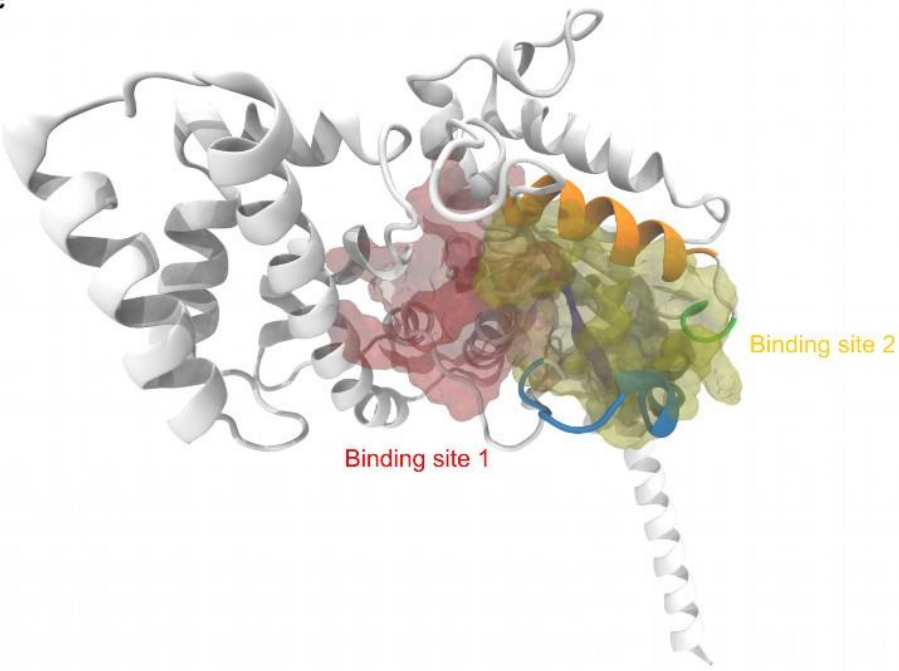

Figure S12. Computationally predicted binding sites on Gai. The Fig. shows the three major binding sites predicted by the DoGSiteScorer ${ }^{15,16}$ algorithm used via SeeSAR (version 10.1, www.biosolveit.de/SeeSAR). The experimentally determined GDP binding site on Gai was correctly predicted, shown as binding site 1 (red surface containing 35 residues). A second binding site (yellow surface containing 21 residues) predicted here eventually turned out to be the best binding site for the peptides used in this study as determined by independent docking simulations. A third binding site (gray surface comprising of 15 residues) to which the best binding peptide

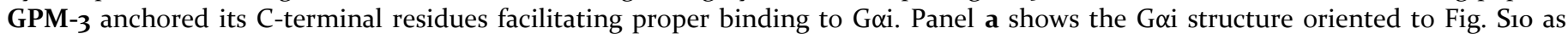
reference, panel $\mathbf{b}$ shows a top view of the protein making all three predicted binding sides visibly oriented, while panel $\mathbf{c}$ shows a side view of the protein focusing on predicted binding sites 1 and 2 overlapping each other's molecular surfaces. This visualization is an indicator that peptide binding to binding site 2 will have a consequent effect on binding site 1 that houses the GDP molecule. 
a

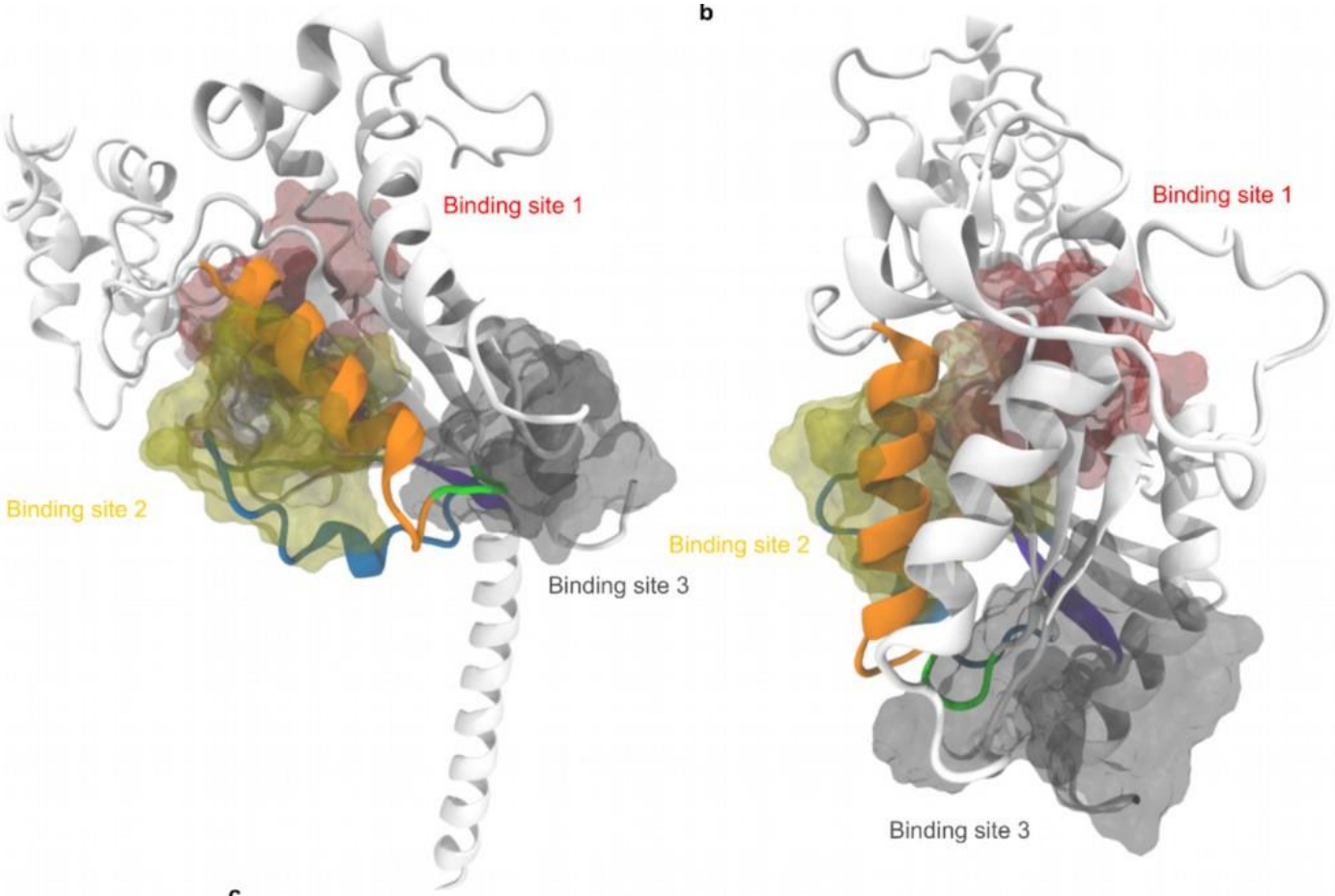

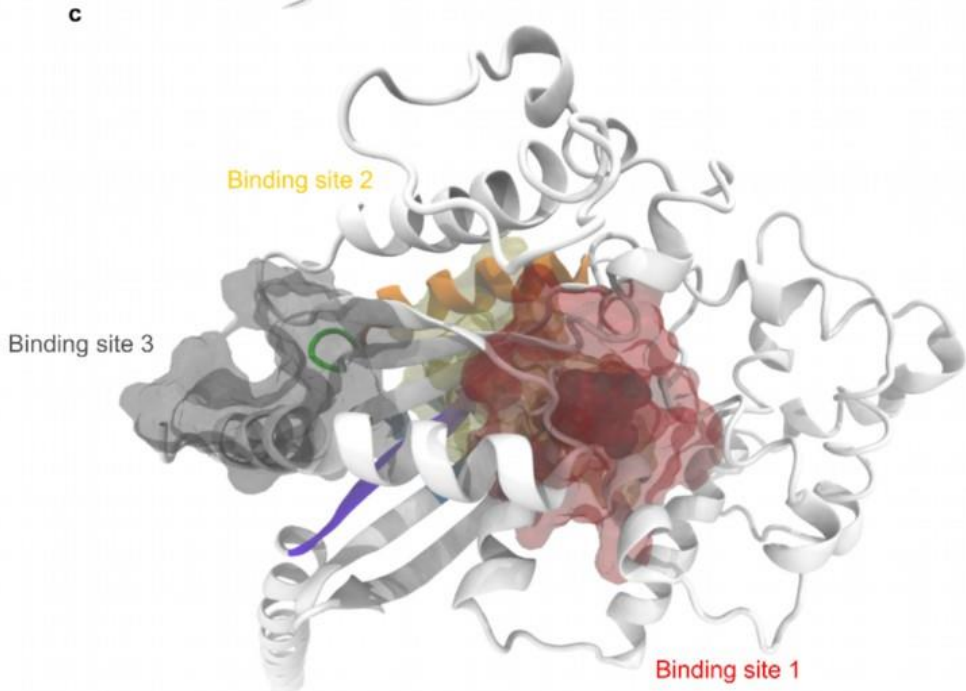

Figure S13. Computationally predicted binding sites on Gas. The Fig. shows the three major binding sites on (PDB 6EG8 ${ }^{14}-\mathrm{Chain}$ I) G $\alpha$ s, predicted by the DoGSiteScorer ${ }^{15,16}$ algorithm used via SeeSAR (version 10.1, www.biosolveit.de/SeeSAR). The experimentally determined GDP binding site on Gas was correctly predicted, shown as binding site 1 (red surface containing 29 residues). A second binding site (yellow surface containing 27 residues) predicted here eventually turned out to be the best binding site for the peptides used in this study as determined by independent docking simulations. A third binding site (gray surface comprising of 17 residues) to which the peptide GPM-1 Y 5 A bound was also predicted. Panels $\mathbf{a}, \mathbf{b}$ and $\mathbf{c}$ show different orientations of the protein to reveal the fact that there is a large overlap between the residues of binding site 1 and 2 . This visualization is an indicator that peptide binding to binding site 2 will have a consequent effect on binding site 1 that houses the GDP molecule. 


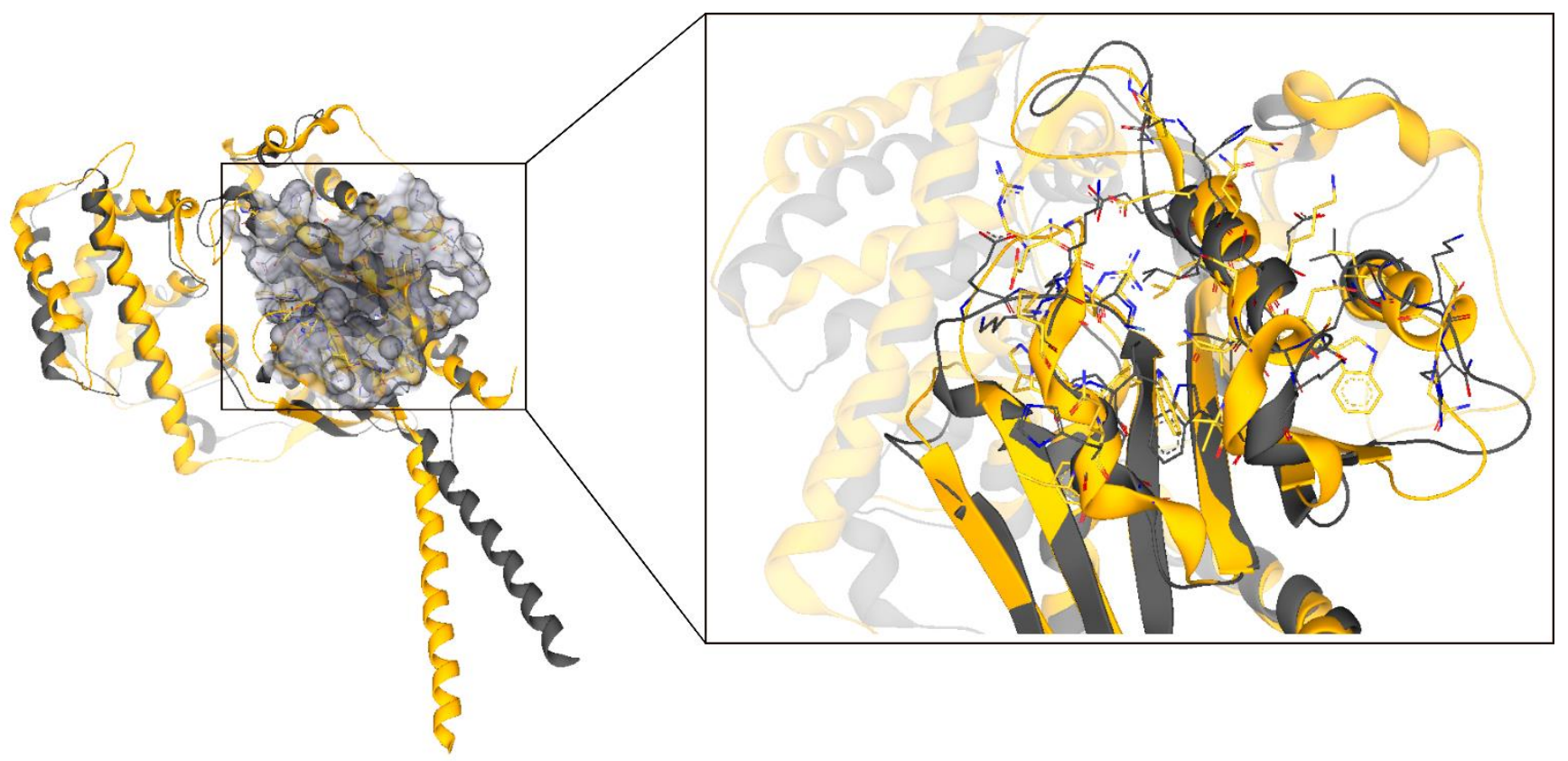

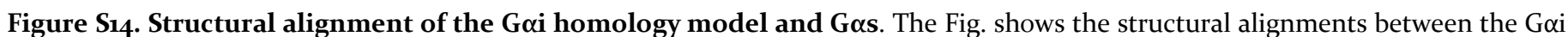
homology model used in the current study (grey) and the Gas subunit (orange) extracted from the X-ray crystallographic structure of the GDP-bound Gas heterotrimer (PDB 6EG8 ${ }^{14}$ - Chain I). The GPM-1 binding site was isolated (transparent grey surface) on the homology model used as the basis of the structural alignment in SeeSAR. The alignment indicates an overall o.8 $\AA$ RMSD between 26 aligned residues between the binding sites of the two structures and an overall RMSD of $1.42 \AA$ over 291 aligned residues with $43 \%$ sequence identity. 

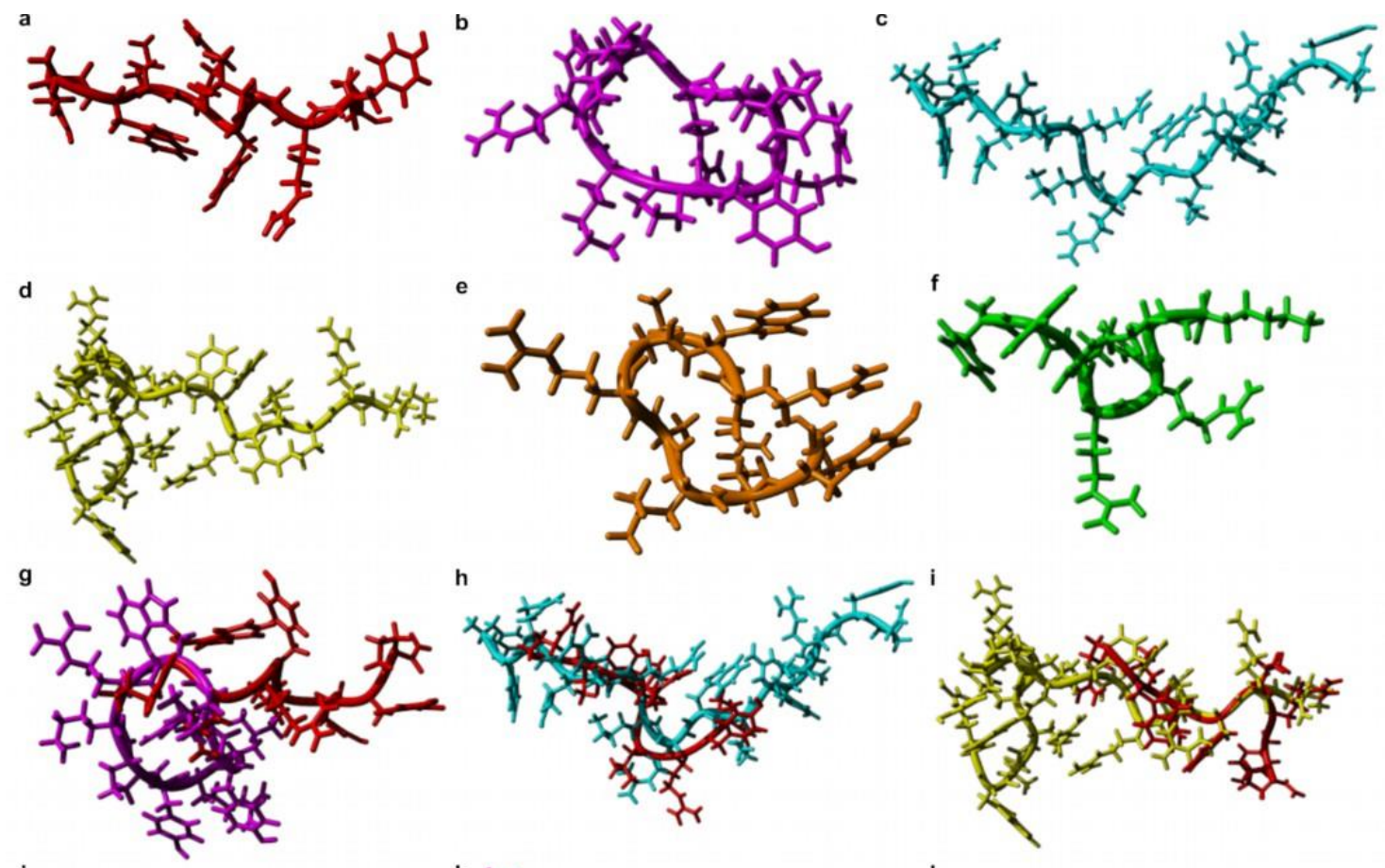

j
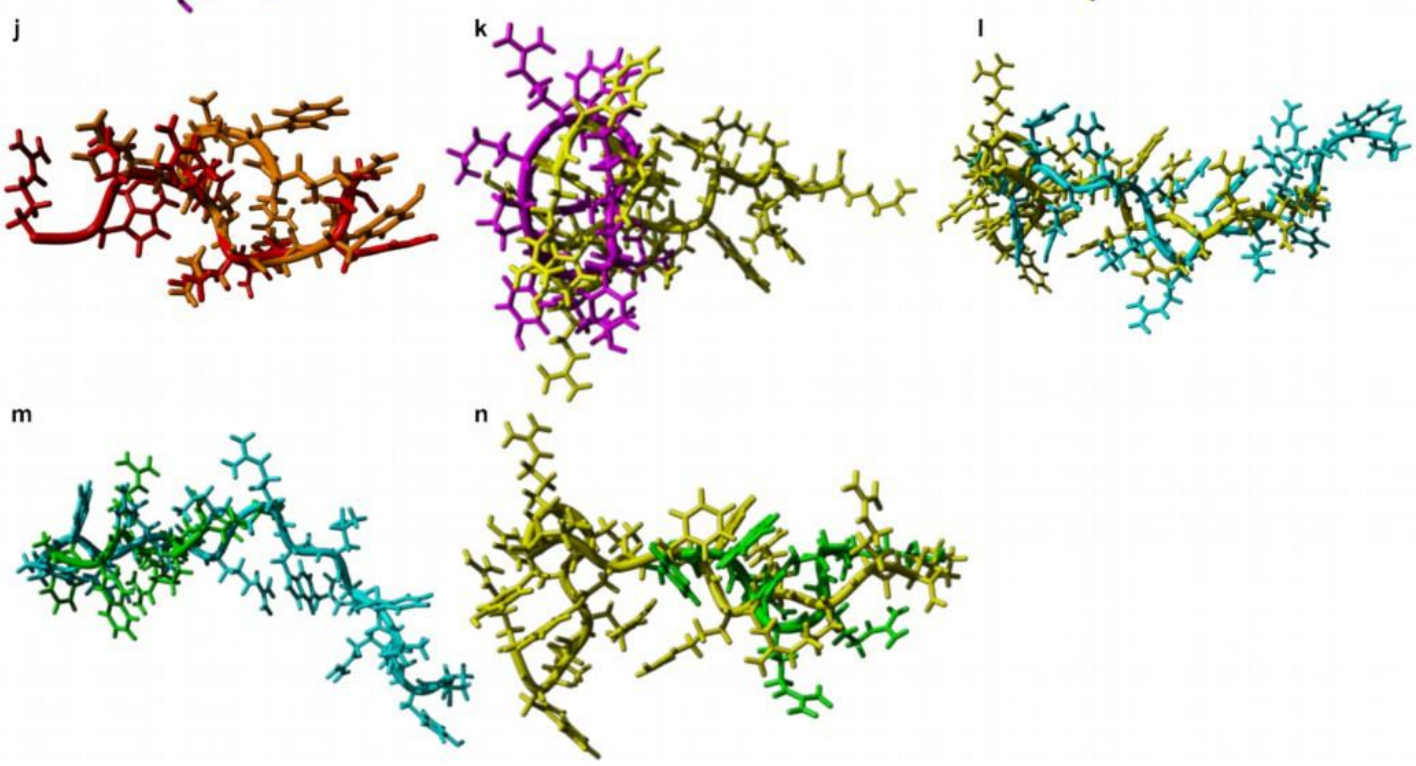

Figure S15. Computationally designed peptide structures and structural alignments. The Fig. shows the final snapshots of the 100 ns MD simulation of the peptides GPM-1 (red, a), GPM-1b (magenta, b), GPM-1c (cyan, c), GPM-1d (yellow, d), GPM-1 Y5A (orange, e) and, peptide $\mathbf{1 5}$ (green, f) which are used as inputs for molecular docking simulations. Panels g-n show structural alignments between GPM-1 and GPM-1b (panel g), GPM-1 and GPM-1c (panel h), GPM-1 and GPM-1d (panel i), GPM-1 and GPM-1 Y5A (panel j) GPM-1b and GPM-1d (panel k), GPM-1c and GPM-1d (panel 1), peptide 15 and GMP-1c (panel $\mathbf{m}$ ), peptide $\mathbf{1 5}$ and GMP-1d (panel n). All structural alignments were done using the MUSTANG algorithm ${ }^{31-33,35-36,38-39}$. 

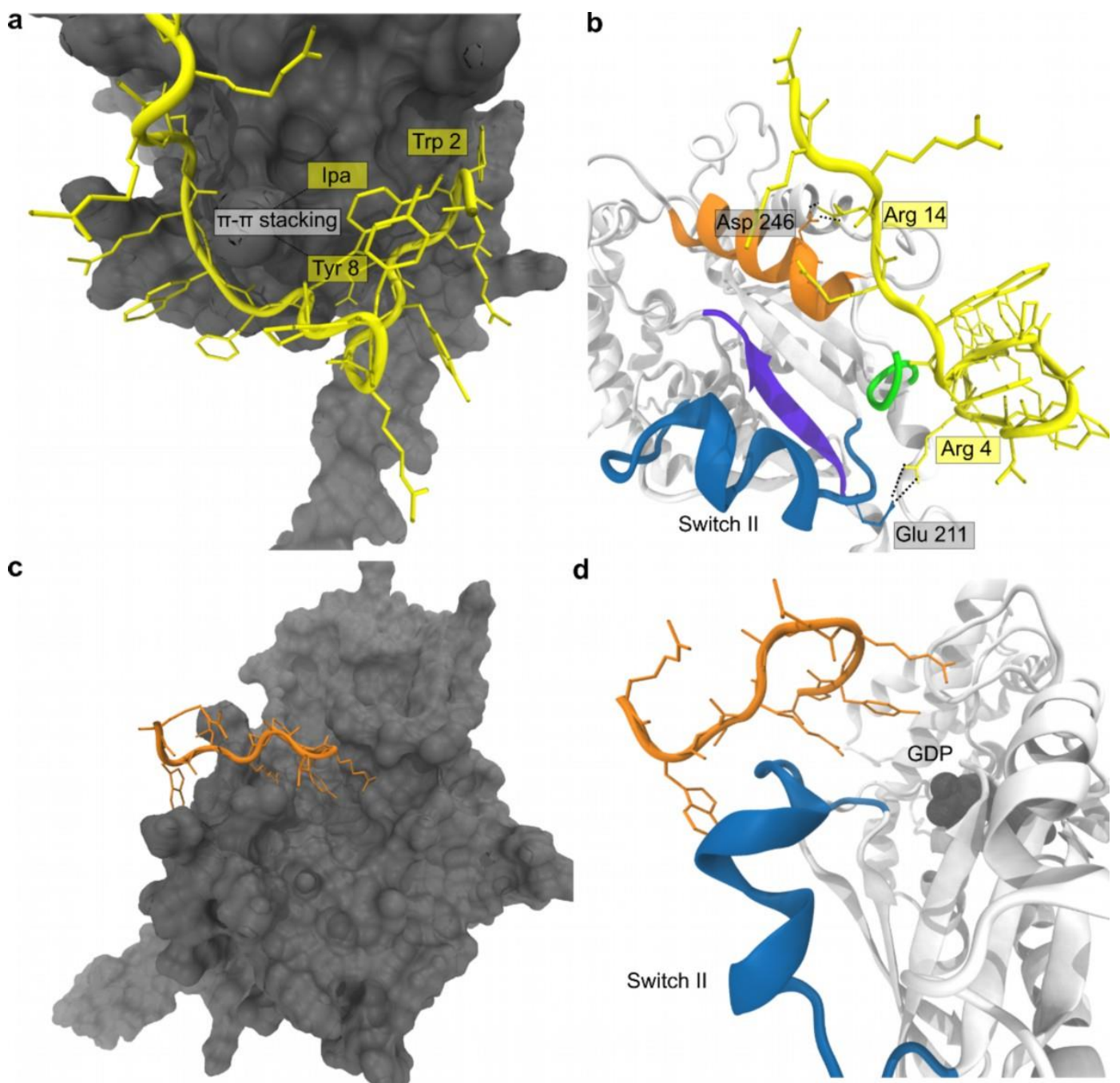

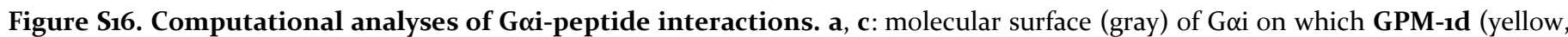
a) and GPM-1 Y5A (orange, c) are bound respectively. In a, the side chains involved in hydrophobic interactions with Gai and intramolecular $\pi$ - $\pi$-stacking interactions are labeled. b: G $\alpha$ i structure (white cartoon) with Switch II (blue), $\alpha_{3}$ (orange), $\beta_{1}$ (violet), and $\alpha_{3}-\beta_{5}$ loop (green) depicted. The bound conformation of GPM-1d (yellow), with the hydrogen bonding (black sticks) partners labeled. d: in simulation, GPM-1 Y5A (orange) dissociates from its initial bound state and is found close to the Switch II region (blue), held only by long electrostatic interactions, and no hydrogen bonds are observed. 


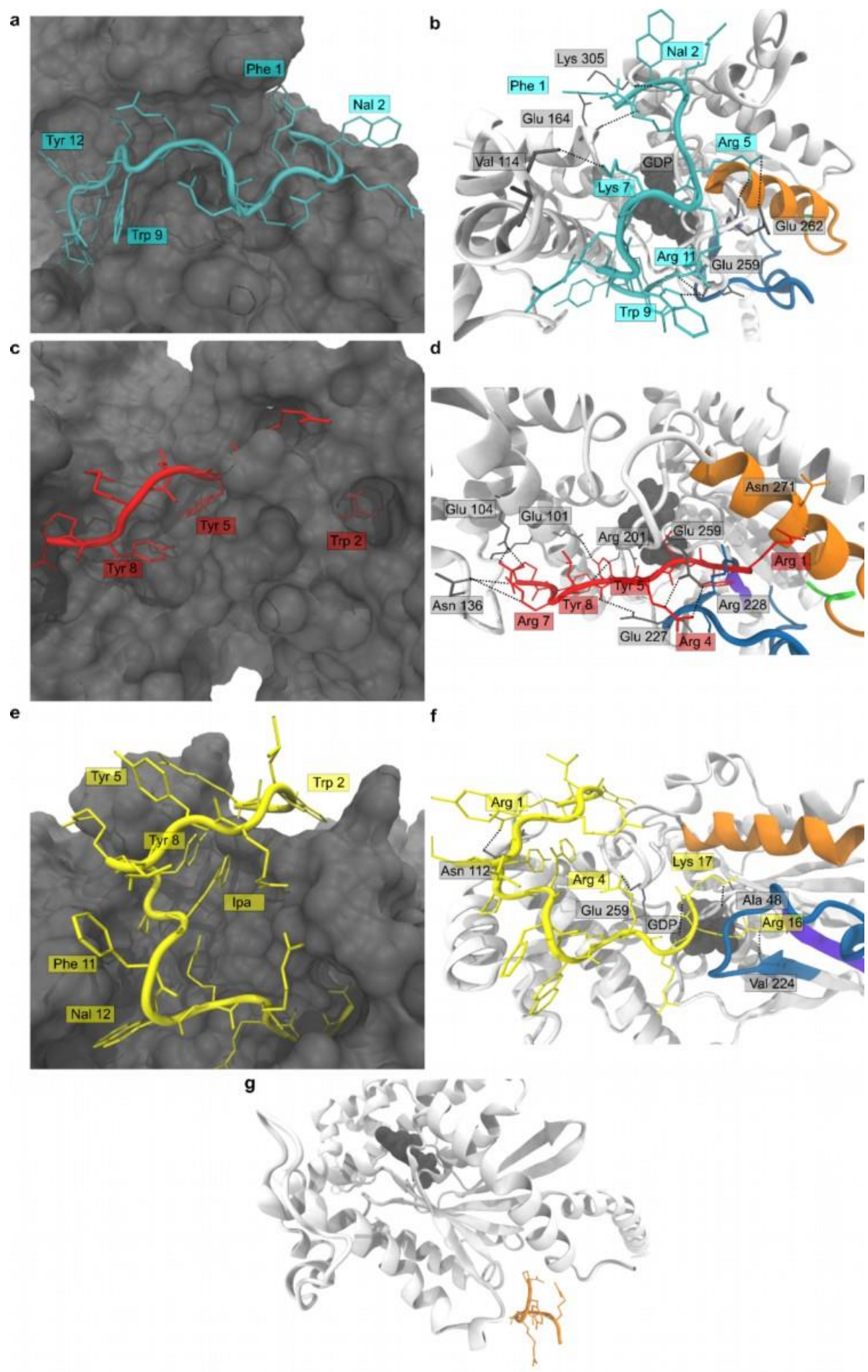

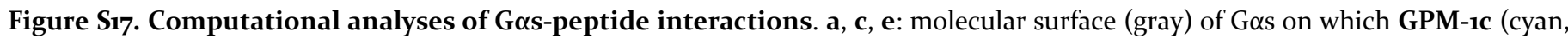
a), GPM-1 (red, c) and GPM-1d (yellow, e) are bound respectively. The side chains involved in hydrophobic interactions with Gas and intramolecular $\pi$ - $\pi$-stacking interactions are labeled. In panels $\mathbf{b}, \mathbf{d}, \mathbf{f}, \mathbf{g}$, the protein $\mathrm{G} \alpha$ s is shown as a white cartoon with the different structural elements color coded as follows: Switch II (blue), $\alpha_{3}$ (orange), $\beta_{1}$ (violet), and $\alpha_{3}-\beta_{5}$ loop (green), and the GDP molecule shown as gray spheres. In the panels b, d, f, the bound conformations of GPM-1c (cyan, b), GPM-1(red, d), and GMP-1d (yellow, f) are shown with the residues involved in H-bonded interactions (black dotted lines) marked and labeled. Panel $\mathbf{g}$ shows the full Gas protein as a white cartoon and (un)bound conformation of GPM-1 Y 5 A shown to explain that it has been dislodged from its bound state during the course of the simulation. 
a

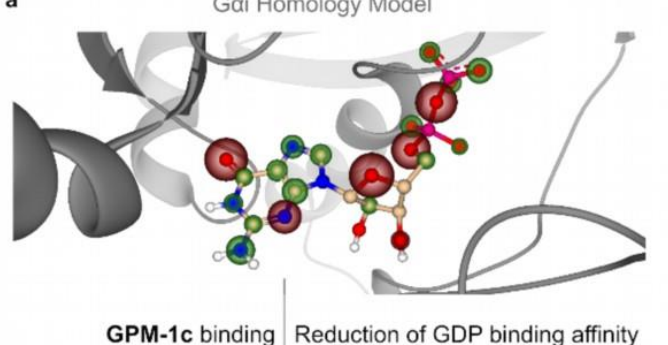

b Gas Structure (PDB 6EG8, Chain I)

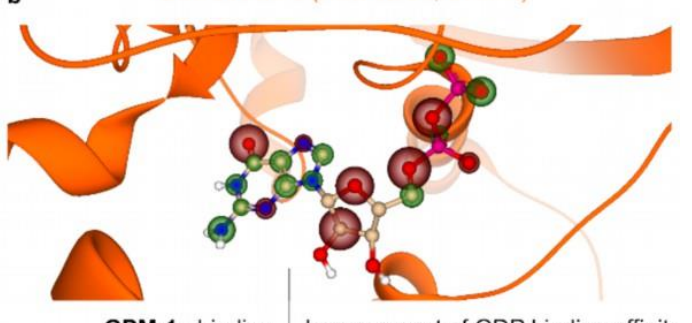

GPM-1c binding Improvement of GDP binding affinity
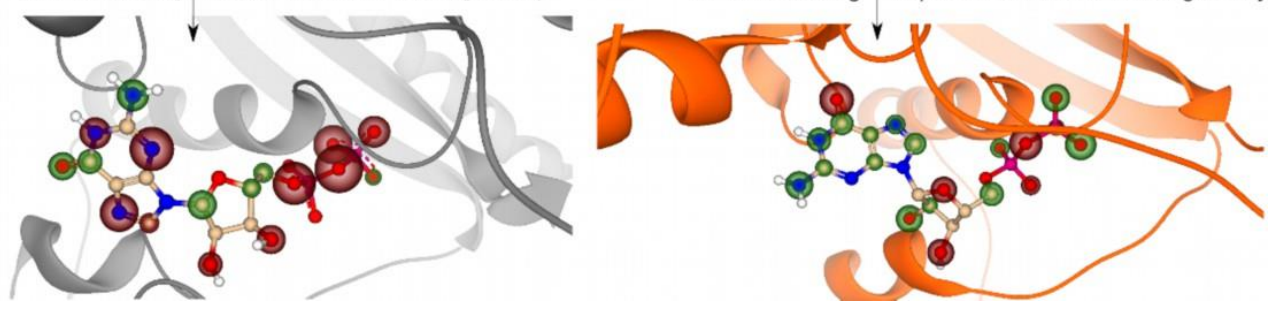

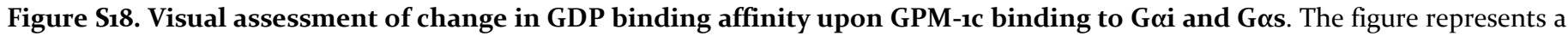

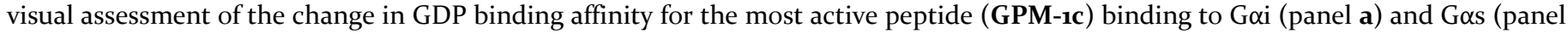
b). The GDP molecule is represented as beige sticks with the atomic contributions to binding affinities computed by the HYDE scoring function ${ }^{36,40}$ in the molecular modeling program SeeSAR. A visual representation of the affinities is shown as translucent spheres (HYDE Coronas, https://www.biosolveit.de/products/\#HYDE). Green coronas represent positive contributions to the binding affinities while red coronas denote unfavorable contributions determined based on the contribution of $\mathrm{H}$-bonding and desolvation energies to the binding affinity. The size of the coronas is proportional to the underlying HYDE energy values. In a (Gai, gray cartoons), the binding of GPM-1c results in the reduction of GDP binding affinity deduced from the increase in the number of red coronas relating to unfavorable atomic interactions, while in $\mathbf{b}$ (Gas, orange cartoon), the opposite is observed, i.e., the reduction in the number of red coronas indicating an improvement in the GDP binding affinity. In both a and $\mathbf{b}$ the top structure denotes the initial structure and the lower part denotes the MD snapshot at 5ons. This is an additional visual representation supplementing the numeric MMPBSA binding energies extracted from the MD trajectories as furnished in Tables S11 and S12. 


\section{Supporting Tables}

Table S1. Hit sequences of all 101 identified hits of the one-bead-one-compound (OBOC) library screening.

\begin{tabular}{|c|c|c|c|c|c|c|c|c|c|c|c|c|c|c|c|c|c|c|c|}
\hline No. & -4 & -3 & -2 & -1 & 0 & +1 & +2 & +3 & +4 & No. & -4 & -3 & -2 & -1 & 0 & +1 & +2 & +3 & +4 \\
\hline 1 & $A$ & $\mathrm{~T}$ & $\mathrm{G}$ & $\mathrm{H}$ & $\mathrm{Y}$ & $\mathrm{K}$ & $Q$ & $Y$ & $D$ & 52 & W & W & $\mathrm{P}$ & $\mathrm{G}$ & $\mathrm{H}$ & $\mathrm{R}$ & $F$ & 1 & A \\
\hline 2 & $\mathrm{~K}$ & V & $\mathrm{R}$ & $M$ & $Y$ & $E$ & $E$ & 1 & $E$ & 53 & $\mathrm{~T}$ & $\mathrm{R}$ & $P$ & W & $\mathrm{H}$ & $\mathrm{H}$ & $\mathrm{R}$ & $M$ & A \\
\hline 3 & $\mathrm{Y}$ & $\mathrm{K}$ & $\mathrm{K}$ & $\mathrm{R}$ & $Y$ & $Y$ & $\mathrm{G}$ & $\mathrm{G}$ & $\mathrm{F}$ & 54 & $F$ & $\mathrm{~T}$ & $\mathrm{G}$ & $\mathrm{N}$ & $\mathrm{H}$ & A & $L$ & $Q$ & D \\
\hline 4 & 1 & $\mathrm{~K}$ & $F$ & $\mathrm{P}$ & $Y$ & $\mathrm{R}$ & $\mathrm{R}$ & $\mathrm{M}$ & $\mathrm{F}$ & 55 & $Y$ & $\mathrm{D}$ & $\mathrm{G}$ & $\mathrm{R}$ & $\mathrm{H}$ & $L$ & $\mathrm{R}$ & $\mathrm{P}$ & $E$ \\
\hline 5 & D & W & $\mathrm{N}$ & $\mathrm{R}$ & $Y$ & $\mathrm{~V}$ & $\mathrm{G}$ & $\mathrm{F}$ & $\mathrm{G}$ & 56 & $\mathrm{G}$ & $\mathrm{R}$ & A & $\mathrm{F}$ & $\mathrm{H}$ & $S$ & $Y$ & $\mathrm{P}$ & $E$ \\
\hline 6 & $\mathrm{~N}$ & W & $A$ & $\mathrm{H}$ & $Y$ & $\mathrm{~V}$ & A & 1 & $\mathrm{G}$ & 57 & $\mathrm{~N}$ & W & $Q$ & $\mathrm{~N}$ & $\mathrm{H}$ & $\mathrm{P}$ & $\mathrm{F}$ & $A$ & $\mathrm{G}$ \\
\hline 7 & A & W & $\mathrm{L}$ & $S$ & $Y$ & $Y$ & $\mathrm{H}$ & $\mathrm{N}$ & $\mathrm{G}$ & 58 & $F$ & $\mathrm{~K}$ & $\mathrm{H}$ & $\mathrm{N}$ & $\mathrm{H}$ & A & $S$ & $\mathrm{~F}$ & $\mathrm{G}$ \\
\hline 8 & $\mathrm{P}$ & $\mathrm{K}$ & A & $\mathrm{T}$ & $Y$ & $\mathrm{~T}$ & $Q$ & $\mathrm{R}$ & $\mathrm{G}$ & 59 & $Q$ & W & $\mathrm{K}$ & $\mathrm{H}$ & $\mathrm{H}$ & W & $Y$ & $\mathrm{Q}$ & $\mathrm{G}$ \\
\hline 9 & $\mathrm{R}$ & $\mathrm{K}$ & $S$ & W & $Y$ & $L$ & $\mathrm{~F}$ & A & $\mathrm{H}$ & 60 & $\mathrm{G}$ & $\mathrm{F}$ & W & $\mathrm{R}$ & $\mathrm{H}$ & $P$ & $Y$ & $\mathrm{R}$ & $\mathrm{G}$ \\
\hline 10 & $P$ & $\mathrm{~K}$ & $\mathrm{~K}$ & $\mathrm{~T}$ & $Y$ & $\mathrm{R}$ & W & A & $\mathrm{H}$ & 61 & $M$ & $\mathrm{Y}$ & $Y$ & $Y$ & $\mathrm{H}$ & $\mathrm{K}$ & V & $\mathrm{R}$ & $\mathrm{H}$ \\
\hline 11 & W & $\mathrm{G}$ & $\mathrm{R}$ & $S$ & $Y$ & $S$ & $\mathrm{H}$ & $\mathrm{P}$ & $\mathrm{H}$ & 62 & $M$ & $Y$ & $Y$ & $Y$ & $\mathrm{H}$ & $\mathrm{K}$ & V & $\mathrm{R}$ & $\mathrm{H}$ \\
\hline 12 & $Q$ & $\mathrm{~T}$ & A & $Y$ & $Y$ & $\mathrm{~F}$ & $\mathrm{~K}$ & $Q$ & $\mathrm{H}$ & 63 & $\mathrm{R}$ & A & $\mathrm{R}$ & $\mathrm{T}$ & $\mathrm{H}$ & $\mathrm{F}$ & W & I & I \\
\hline 13 & $A$ & $\mathrm{H}$ & $D$ & $\mathrm{~T}$ & $Y$ & $\mathrm{R}$ & $F$ & $\mathrm{G}$ & 1 & 64 & $Q$ & $\mathrm{R}$ & $Y$ & $\mathrm{~L}$ & $\mathrm{H}$ & $L$ & $\mathrm{~L}$ & $\mathrm{R}$ & I \\
\hline 14 & W & $P$ & $\mathrm{~K}$ & $\mathrm{~N}$ & $Y$ & $\mathrm{R}$ & $Q$ & $\mathrm{~K}$ & I & 65 & $F$ & $\mathrm{H}$ & $Q$ & W & $\mathrm{H}$ & $\mathrm{R}$ & $\mathrm{T}$ & $\mathrm{Q}$ & $\mathrm{K}$ \\
\hline 15 & W & $P$ & $\mathrm{~F}$ & A & $Y$ & $\mathrm{~T}$ & $\mathrm{~K}$ & $\mathrm{~N}$ & 1 & 66 & $M$ & A & $\mathrm{T}$ & $Y$ & $\mathrm{H}$ & $\mathrm{P}$ & $Y$ & $Q$ & $\mathrm{~K}$ \\
\hline 16 & $F$ & $D$ & $P$ & $S$ & $Y$ & $F$ & $\mathrm{R}$ & $\mathrm{N}$ & I & 67 & $\mathrm{~N}$ & W & $\mathrm{Q}$ & A & $\mathrm{H}$ & $\mathrm{V}$ & V & $S$ & $\mathrm{~K}$ \\
\hline 17 & $\mathrm{G}$ & $P$ & $Y$ & $\mathrm{G}$ & $\mathrm{Y}$ & $S$ & W & $\mathrm{R}$ & I & 68 & $\mathrm{E}$ & $\mathrm{T}$ & $\mathrm{L}$ & $\mathrm{H}$ & $\mathrm{H}$ & $\mathrm{P}$ & V & V & $\mathrm{K}$ \\
\hline 18 & $\mathrm{~N}$ & $M$ & $M$ & V & $Y$ & $\mathrm{H}$ & $\mathrm{R}$ & $\mathrm{K}$ & $\mathrm{K}$ & 69 & $\mathrm{P}$ & $M$ & $M$ & A & $\mathrm{H}$ & $M$ & $S$ & $\mathrm{G}$ & L \\
\hline 19 & $\mathrm{Y}$ & $Y$ & $E$ & $\mathrm{~K}$ & $Y$ & $\mathrm{~T}$ & $\mathrm{R}$ & $\mathrm{T}$ & $\mathrm{K}$ & 70 & $M$ & $\mathrm{~N}$ & $L$ & $Y$ & $\mathrm{H}$ & $F$ & $\mathrm{D}$ & $\mathrm{H}$ & $\mathrm{L}$ \\
\hline 20 & $D$ & $F$ & 1 & A & $Y$ & A & $\mathrm{N}$ & W & $\mathrm{K}$ & 71 & $\mathrm{R}$ & $\mathrm{R}$ & $\mathrm{L}$ & $\mathrm{V}$ & $\mathrm{H}$ & $\mathrm{H}$ & $\mathrm{R}$ & $\mathrm{V}$ & L \\
\hline 21 & $\mathrm{P}$ & I & A & $\mathrm{R}$ & $Y$ & A & $\mathrm{R}$ & W & $\mathrm{K}$ & 72 & $S$ & $S$ & $M$ & $F$ & $\mathrm{H}$ & I & $\mathrm{G}$ & $\mathrm{L}$ & $\mathrm{N}$ \\
\hline 22 & $\mathrm{~N}$ & W & $\mathrm{G}$ & A & $Y$ & $L$ & $\mathrm{D}$ & $\mathrm{G}$ & $L$ & 73 & $F$ & $\mathrm{~K}$ & $\mathrm{~N}$ & $\mathrm{P}$ & $\mathrm{H}$ & $\mathrm{P}$ & $Y$ & $\mathrm{~N}$ & $\mathrm{~N}$ \\
\hline 23 & $\mathrm{~N}$ & W & $\mathrm{G}$ & A & $Y$ & $L$ & $\mathrm{D}$ & $\mathrm{G}$ & $L$ & 74 & $\mathrm{H}$ & $\mathrm{K}$ & $\mathrm{E}$ & $M$ & $\mathrm{H}$ & $S$ & $E$ & 1 & $M$ \\
\hline 24 & $\mathrm{P}$ & $\mathrm{H}$ & W & $M$ & $Y$ & I & $D$ & I & $\mathrm{L}$ & 75 & $\mathrm{R}$ & I & $\mathrm{N}$ & W & $\mathrm{H}$ & $\mathrm{G}$ & $\mathrm{G}$ & $\mathrm{N}$ & $M$ \\
\hline 25 & $\mathrm{~N}$ & $F$ & I & $\mathrm{R}$ & $\mathrm{Y}$ & A & $\mathrm{H}$ & $\mathrm{K}$ & $\mathrm{L}$ & 76 & $\mathrm{R}$ & $\mathrm{K}$ & W & $\mathrm{T}$ & $\mathrm{H}$ & $D$ & $\mathrm{G}$ & $\mathrm{R}$ & $M$ \\
\hline 26 & W & $F$ & $Q$ & $S$ & $Y$ & W & $\mathrm{G}$ & $\mathrm{N}$ & $L$ & 77 & $\mathrm{~L}$ & $M$ & $\mathrm{D}$ & $Y$ & $\mathrm{H}$ & $F$ & $\mathrm{R}$ & $\mathrm{R}$ & $M$ \\
\hline 27 & $\mathrm{R}$ & $\mathrm{K}$ & $A$ & $S$ & $Y$ & I & $\mathrm{H}$ & $\mathrm{Q}$ & $\mathrm{N}$ & 78 & $Q$ & $\mathrm{R}$ & $A$ & $\mathrm{R}$ & $\mathrm{H}$ & $\mathrm{D}$ & $S$ & $F$ & $Q$ \\
\hline 28 & $S$ & W & $\mathrm{T}$ & $\mathrm{M}$ & $Y$ & $P$ & $F$ & $\mathrm{R}$ & $\mathrm{N}$ & 79 & I & $\mathrm{R}$ & $\mathrm{Q}$ & $\mathrm{H}$ & $\mathrm{H}$ & $\mathrm{K}$ & $\mathrm{T}$ & $\mathrm{T}$ & $Q$ \\
\hline 29 & $\mathrm{~T}$ & $\mathrm{~F}$ & $D$ & $\mathrm{R}$ & $\mathrm{Y}$ & $\mathrm{T}$ & $A$ & $\mathrm{~L}$ & $M$ & 80 & $\mathrm{~V}$ & $\mathrm{R}$ & V & $Y$ & $\mathrm{H}$ & $\mathrm{H}$ & $\mathrm{N}$ & $\mathrm{G}$ & $\mathrm{R}$ \\
\hline 30 & $Q$ & $L$ & $\mathrm{~K}$ & A & $Y$ & V & A & $S$ & $M$ & 81 & $S$ & $S$ & $\mathrm{H}$ & V & $\mathrm{H}$ & $\mathrm{K}$ & $F$ & $M$ & $\mathrm{R}$ \\
\hline 31 & $Q$ & A & $\mathrm{N}$ & $\mathrm{H}$ & $Y$ & $M$ & W & $Y$ & $\mathrm{M}$ & 82 & W & $\mathrm{P}$ & $\mathrm{Y}$ & $D$ & $\mathrm{H}$ & $\mathrm{R}$ & $F$ & $M$ & $\mathrm{R}$ \\
\hline 32 & V & $L$ & $\mathrm{~K}$ & $F$ & $Y$ & $E$ & $F$ & $\mathrm{G}$ & $\mathrm{P}$ & 83 & $Q$ & $M$ & $F$ & $S$ & $\mathrm{H}$ & $M$ & $\mathrm{H}$ & $P$ & $\mathrm{R}$ \\
\hline 33 & $\mathrm{G}$ & $E$ & $\mathrm{P}$ & $\mathrm{R}$ & $Y$ & $\mathrm{~F}$ & $\mathrm{~K}$ & $Y$ & $\mathrm{P}$ & 84 & $P$ & $\mathrm{D}$ & $\mathrm{R}$ & $D$ & $\mathrm{H}$ & $\mathrm{H}$ & $\mathrm{K}$ & $Y$ & $\mathrm{R}$ \\
\hline 34 & $\mathrm{R}$ & W & $\mathrm{L}$ & $\mathrm{R}$ & $Y$ & $L$ & $\mathrm{R}$ & $Y$ & $\mathrm{P}$ & 85 & $\mathrm{~K}$ & $\mathrm{D}$ & $\mathrm{G}$ & $\mathrm{L}$ & $\mathrm{H}$ & $\mathrm{R}$ & $\mathrm{V}$ & $Y$ & $\mathrm{R}$ \\
\hline 35 & $S$ & I & $\mathrm{N}$ & $Y$ & $Y$ & $\mathrm{~F}$ & $S$ & $M$ & $Q$ & 86 & $\mathrm{~T}$ & $S$ & $\mathrm{R}$ & $Y$ & $\mathrm{H}$ & $M$ & $\mathrm{H}$ & $\mathrm{R}$ & I \\
\hline
\end{tabular}




\begin{tabular}{|c|c|c|c|c|c|c|c|c|c|c|c|c|c|c|c|c|c|c|c|}
\hline 36 & $\mathrm{~F}$ & $S$ & $\mathrm{R}$ & $\mathrm{R}$ & Y & $\mathrm{R}$ & $S$ & $P$ & $Q$ & 87 & W & V & $\mathrm{Q}$ & $\mathrm{R}$ & $\mathrm{H}$ & $P$ & Y & A & $\mathrm{V}$ \\
\hline 37 & $S$ & $Y$ & $M$ & D & Y & $\mathrm{F}$ & $\mathrm{H}$ & A & $\mathrm{R}$ & 88 & W & $\mathrm{F}$ & $Q$ & A & $\mathrm{H}$ & K & $\mathrm{F}$ & L & V \\
\hline 38 & $\mathrm{H}$ & $\mathrm{H}$ & $Y$ & $\mathrm{~N}$ & Y & $\mathrm{R}$ & $Y$ & $\mathrm{~T}$ & $\mathrm{R}$ & 89 & $P$ & M & $\mathrm{R}$ & G & $\mathrm{H}$ & 1 & M & $Q$ & V \\
\hline 39 & $\mathrm{~F}$ & A & $N$ & G & $\mathrm{Y}$ & $\mathrm{R}$ & W & Y & $\mathrm{R}$ & 90 & $P$ & $\mathrm{~F}$ & $R$ & $S$ & $\mathrm{H}$ & V & $S$ & W & V \\
\hline 40 & $\mathrm{H}$ & $\mathrm{F}$ & $\mathrm{F}$ & $Y$ & Y & D & $\mathrm{Q}$ & Q & $S$ & 91 & $\mathrm{~F}$ & L & G & W & $\mathrm{H}$ & L & G & $\mathrm{N}$ & W \\
\hline 41 & $Q$ & 1 & $\mathrm{~L}$ & K & Y & $Y$ & $\mathrm{~N}$ & $\mathrm{~F}$ & $\mathrm{~T}$ & 92 & V & $\mathrm{T}$ & 1 & P & $\mathrm{H}$ & W & $S$ & M & W \\
\hline 42 & $\mathrm{~N}$ & W & I & K & Y & $\mathrm{L}$ & G & K & $\mathrm{T}$ & 93 & $\mathrm{R}$ & $\mathrm{Y}$ & $\mathrm{H}$ & I & $\mathrm{H}$ & $\mathrm{E}$ & $Y$ & $\mathrm{H}$ & $Y$ \\
\hline 43 & D & $G$ & $G$ & G & Y & $R$ & $S$ & K & $\mathrm{T}$ & 94 & 1 & $\mathrm{H}$ & W & $\mathrm{T}$ & $\mathrm{H}$ & $\mathrm{H}$ & $\mathrm{H}$ & $\mathrm{K}$ & $Y$ \\
\hline 44 & W & $P$ & $S$ & $\mathrm{H}$ & Y & $R$ & K & Q & $\mathrm{T}$ & 95 & $\mathrm{H}$ & E & W & V & $\mathrm{H}$ & $G$ & $\mathrm{~F}$ & L & $Y$ \\
\hline 45 & $Y$ & L & $\mathrm{K}$ & $\mathrm{H}$ & Y & $\mathrm{H}$ & $S$ & A & V & 96 & K & $\mathrm{R}$ & $\mathrm{R}$ & $\mathrm{T}$ & $\mathrm{H}$ & A & $\mathrm{H}$ & $P$ & $Y$ \\
\hline 46 & $\mathrm{R}$ & $\mathrm{H}$ & D & $\mathrm{H}$ & Y & $\mathrm{N}$ & A & Y & V & 97 & K & $\mathrm{K}$ & $S$ & K & $\mathrm{H}$ & $P$ & W & $\mathrm{R}$ & $Y$ \\
\hline 47 & $\mathrm{~N}$ & $\mathrm{~T}$ & $\mathrm{~K}$ & $Q$ & Y & $S$ & $S$ & A & $Y$ & 98 & $\mathrm{R}$ & $Q$ & $P$ & $Y$ & C & $P$ & $Y$ & $\mathrm{H}$ & W \\
\hline 48 & $\mathrm{R}$ & P & $\mathrm{L}$ & L & $Y$ & $\mathrm{H}$ & K & 1 & $Y$ & 99 & Y & $Y$ & $\mathrm{~N}$ & V & C & $\mathrm{H}$ & G & 1 & $\mathrm{~L}$ \\
\hline 49 & $Q$ & D & $\mathrm{H}$ & $P$ & $Y$ & A & $\mathrm{Q}$ & K & $Y$ & 100 & D & $S$ & 1 & G & C & $\mathrm{F}$ & $\mathrm{N}$ & $Q$ & $F$ \\
\hline 50 & $\mathrm{~N}$ & W & $\mathrm{R}$ & $\mathrm{N}$ & $Y$ & V & A & $\mathrm{L}$ & $Y$ & 101 & $\mathrm{~F}$ & $\mathrm{Q}$ & Y & $Q$ & C & $\mathrm{R}$ & K & $\mathrm{H}$ & $\mathrm{F}$ \\
\hline 51 & $\mathrm{R}$ & $\mathrm{H}$ & D & D & $Y$ & $S$ & $Y$ & $Q$ & D & & & & & & & & & & \\
\hline
\end{tabular}

$\mathrm{M}=$ norleucine, as used in an earlier study 37.

Table S2. Multiple sequence alignment by Clustal Omega $(\mathrm{O} \text { 1.2.4 })^{41}$ of the 13 selected screening-derived hits.

\begin{tabular}{|c|c|c|c|c|c|c|c|c|c|c|c|c|c|c|c|}
\hline peptide & & & & $\Phi$ & $\zeta$ & W & $\Phi$ & {$[+/-]$} & $\Omega$ & $\Phi$ & & & & & \\
\hline 1 & - & - & - & - & $\mathrm{R}$ & W & $\mathbf{L}$ & $\mathbf{R}$ & $\mathbf{Y}$ & $\mathbf{L}$ & $\mathrm{R}$ & $\mathrm{Y}$ & $\mathrm{P}$ & - & - \\
\hline 2 & - & - & - & - & $\mathbf{N}$ & W & G & A & $\mathbf{Y}$ & $\mathbf{L}$ & D & G & $\mathrm{L}$ & - & - \\
\hline 7 & - & - & - & & & & $\mathbf{F}$ & $\mathrm{Q}$ & $\mathbf{Y}$ & Q & C & $\mathrm{R}$ & K & $\mathrm{H}$ & $\mathrm{F}$ \\
\hline 10 & & $\mathrm{~S}$ & $\mathrm{~S}$ & $\mathbf{M}$ & F & $\mathrm{H}$ & I & G & $\mathrm{L}$ & $\mathrm{N}$ & - & - & - & - & - \\
\hline 3 & - & - & - & - & $\mathrm{N}$ & F & I & $\mathbf{R}$ & $\mathbf{Y}$ & A & $\mathrm{H}$ & K & $\mathrm{L}$ & - & - \\
\hline 4 & - & - & - & - & - & W & $\mathrm{P}$ & $\mathbf{K}$ & $\mathrm{N}$ & $\mathbf{Y}$ & $\mathrm{R}$ & Q & K & I & - \\
\hline 12 & - & - & - & - & $\mathbf{Q}$ & I & $\mathbf{L}$ & $\mathbf{K}$ & $\mathbf{Y}$ & $\mathbf{Y}$ & $\mathrm{N}$ & $\mathrm{F}$ & $\mathrm{T}$ & - & - \\
\hline 11 & - & K & V & $\mathrm{R}$ & M & Y & E & $\mathbf{E}$ & I & E & - & - & - & - & - \\
\hline 9 & - & - & M & $\mathbf{Y}$ & Y & Y & $\mathrm{H}$ & $\mathbf{K}$ & V & $\mathrm{R}$ & $\mathrm{H}$ & - & - & - & - \\
\hline 5 & - & - & - & - & - & W & V & $\mathrm{Q}$ & $\mathrm{R}$ & $\mathrm{H}$ & $\mathrm{P}$ & $\mathrm{Y}$ & A & $\mathrm{V}$ & - \\
\hline 6 & - & - & $\mathrm{F}$ & $\mathrm{H}$ & $\mathbf{Q}$ & W & $\mathrm{H}$ & $\mathbf{R}$ & $\mathrm{T}$ & $\mathrm{Q}$ & K & - & - & - & - \\
\hline 8 & $\mathrm{~T}$ & $\mathrm{~S}$ & $\mathrm{R}$ & $\mathbf{Y}$ & $\mathrm{H}$ & M & $\mathrm{H}$ & $\mathbf{R}$ & I & - & - & - & - & - & - \\
\hline 13 & - & $P$ & D & $\mathrm{R}$ & D & $\mathrm{H}$ & $\mathrm{H}$ & K & $\mathbf{Y}$ & $\mathrm{R}$ & - & - & - & - & - \\
\hline
\end{tabular}

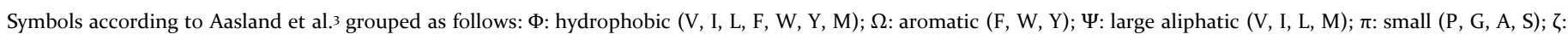
uncharged hydrophilic (N, Q, S, T); [+]: basic (H, K, R) and [-]: acidic amino acids (D, E). The residues of the screening-derived peptides which match the $\Phi \zeta W \Phi[+/-] \Omega \Phi-$ motif are shown in bold letters. The first four peptides $(\mathbf{1}, \mathbf{2}, \mathbf{7}, \mathbf{1 0})$ showed binding towards Gaiı.GDP. M = norleucine (Nle) ${ }^{37}$. 
Table S3. Analytical characterization of peptides prepared in this study.

\begin{tabular}{|c|c|c|c|c|}
\hline No. & Peptide sequence & Mw (Mw theor.) & $\mathrm{HPLC}_{1} 18 \mathrm{t}_{\mathrm{R}}(\mathrm{min})$ & $\operatorname{HPLC~C~} 8 t_{R}(\min )$ \\
\hline GPM-1 & RWLRYLRYP & $1321.73^{\mathrm{a}}(1320.76)$ & $31.63^{\mathrm{d}}$ & $22.72^{\mathrm{e}}$ \\
\hline GPM-1 Y $5 A$ & RWLRALRYP & $1229.74^{\mathrm{a}}(1228.73)$ & $30.30^{d}$ & $25.99^{e}$ \\
\hline GPM-ıb & cyc[KRWLRYLRYP] & $1432.88^{c}(1431.83)$ & $34 \cdot 27^{\mathrm{d}}$ & $15.23^{\mathrm{h}}$ \\
\hline GPM-1C & F(2Nal)RRRRKRWLRYLRYP & $2418.40^{c}(2417.41)$ & $34 \cdot 52^{\mathrm{d}}$ & $14.80^{\mathrm{h}}$ \\
\hline GPM-1d & cyc[RWLRYLRYP]F(2Nal)RRRRK & $2634.50^{c}(2633.46)$ & $39.44^{d}$ & $20.13^{j}$ \\
\hline 2 & NWGAYLDGL & $1007.49^{\mathrm{a}}(1006.49)$ & $16.17^{\mathrm{h}}$ & $15.75^{\mathrm{h}}$ \\
\hline 3 & NFIRYAHKL & $1160.66^{a}(1159.66)$ & $18.70^{e}$ & $18.35^{\mathrm{e}}$ \\
\hline 4 & WPKNYRQKI & $1231.71^{\mathrm{a}}(1230.70)$ & $15.15^{\mathrm{f}}$ & $14.66^{\mathrm{f}}$ \\
\hline 5 & WVQRHPYAV & $1154.62^{\mathrm{a}}(1153.61)$ & $15.28^{\mathrm{f}}$ & $15.04^{f}$ \\
\hline 6 & FHQWHRTQK & $1266.66^{c}(1265.65)$ & $22.05^{\mathrm{g}}$ & $21.44^{\mathrm{g}}$ \\
\hline 7 & FQYQCRKHF & $1255.61^{\mathrm{a}}(1254.61)$ & $15.58^{f}$ & $15.27^{f}$ \\
\hline 8 & TSRYHMHRI & $1181.71^{\mathrm{c}}(1180.66)$ & $14.90^{f}$ & $14.68^{f}$ \\
\hline 9 & MYYYHKVRH & $1277.65^{c}(1276.68)$ & $14.08^{f}$ & $13.93^{f}$ \\
\hline 10 & SSMFHIGLN & $493.77^{\mathrm{b}}(985.53)$ & $14.66^{\mathrm{h}}$ & $14.64^{\mathrm{h}}$ \\
\hline 11 & KVRMYEEIE & $1177.66^{c}(1176.65)$ & $19.16^{\mathrm{e}}$ & $18.93^{\mathrm{e}}$ \\
\hline 12 & QILKYYNFT & $1188.65^{\mathrm{a}}(1187.63)$ & $21.85^{\mathrm{e}}$ & $21.58^{\mathrm{e}}$ \\
\hline 13 & PDRDHHKYR & $1222.57^{\mathrm{C}}(1221.61)$ & $16.31^{\mathrm{i}}$ & $15.38^{\mathrm{i}}$ \\
\hline 14 & KRWLRYLRYP & $1449.89^{c}(1448.85)$ & $30.92^{\mathrm{d}}$ & $21.82^{\mathrm{e}}$ \\
\hline 15 & $\mathrm{~F}(2 \mathrm{Nal}) \mathrm{RRRRK}$ & $1114.69^{c}(1113.68)$ & $25.99^{d}$ & $16.79^{f}$ \\
\hline KB- $75^{2^{42}}$ & H-SRVTWYDFLMEDTKSR-OH & $2034.00^{\mathrm{C}}(2032.97)$ & $36.7 \mathrm{I}^{\mathrm{d}}$ & $17.5^{\mathrm{h}}$ \\
\hline
\end{tabular}

$\mathrm{M}=$ norleucine, as used in an earlier study ${ }^{37}$. All peptides were synthesized as acid amides unless otherwise stated. Mass peaks were detected as a) $[\mathrm{M}+\mathrm{H}]^{+}$and $\left.\mathrm{b}\right)[\mathrm{M}+2 \mathrm{H}]^{2+}$ with LC-ESI-MS and as c) $[\mathrm{M}+\mathrm{H}]^{+}$with MALDI-MS. For analytical RP-HPLC the following gradients were used: $\mathrm{d}$ ) o - $60 \%$ eluent B in 60 min, e) $10-50 \%$ eluent B in 40 min, f) $10-40 \%$ eluent B in 30 min, g) o - 40\% eluent B in 40 min, h) $20-50 \%$ eluent B in 30 min, i) o - $30 \%$ eluent B in 30 min and j) $20-60 \%$ eluent B in 40 min. *All peptides were $>98 \%$ HPLC pure. 
Table S4. Analytical characterization of peptides prepared in this study.

\begin{tabular}{|c|c|c|c|}
\hline No. & Peptide sequence & Mw (Mw theor.) & HPLC C $18 t_{R}(\min )$ \\
\hline Cf-GPM-1 & Cf-RWLRYLRYP & $1679 \cdot 79^{c}(1678.80)$ & $22.82,23.25^{\mathrm{g}}$ \\
\hline Cf-GPM-1 Y5A & Cf-RWLRALRYP & $794.40^{\mathrm{b}}(1586.78)$ & $39.80,40.19^{d}$ \\
\hline FITC-GPM-ıb & сус[K(FITC)RWLRYLRYP] & $1821.83^{\mathrm{c}}(1820.86)$ & $42.75^{\mathrm{d}}$ \\
\hline Cf-GPM-1c & Cf-F(2Nal)RRRRKRWLRYLRYP & $2776.37^{\mathrm{c}}(2775.46)$ & $41.12^{\mathrm{d}}$ \\
\hline FITC-GPM-1d & cyc[RWLRYLRYP]F(2Nal)RRRRK(FITC) & $3023.64^{c}(3022.50)$ & $42.56^{\mathrm{d}}$ \\
\hline $\mathrm{Cf}-2$ & Cf-NWGAYLDGL & $1365.53^{\mathrm{a}}(1364.54)$ & $21.81,22.5^{\mathrm{g}}$ \\
\hline $\mathrm{Cf}-3$ & Cf-NFIRYAHKL & $759.86^{\mathrm{b}}(1517.71)$ & $19.24,20.09^{g}$ \\
\hline Cf-4 & Cf-WPKNYRQKI & $1589.78^{c}(1588.75)$ & $16.09,17.46^{\mathrm{g}}$ \\
\hline $\mathrm{Cf}-5$ & Cf-WVQRHPYAV & $1512.65^{\mathrm{a}}(1511.66)$ & $18.08,19.18^{g}$ \\
\hline Cf-6 & Cf-FHQWHRTQK & $1624.69^{a}(1623.70)$ & $15.46,16.44^{f}$ \\
\hline $\mathrm{Cf}-7$ & Cf-FQYQCRKHF & $1613.67^{\mathrm{a}}(1612.66)$ & $17 \cdot 36,18.24^{\mathrm{g}}$ \\
\hline Cf-8 & Cf-TSRYHMHRI & $1539.70^{a}(1538.71)$ & $13.11,13.86^{\mathrm{f}}$ \\
\hline Cf-9 & Cf-MYYYHKVRH & $818.37^{\mathrm{b}}(1634.73)$ & $17.33,18.7^{g}$ \\
\hline Cf-10 & Cf-SSMFHIGLN & $1344.58^{\mathrm{a}}(1343.58)$ & $22.62,23.70^{\mathrm{g}}$ \\
\hline Cf-11 & Cf-KVRMYEEIE & $1535 \cdot 7^{\mathrm{c}}(1534 \cdot 7 \mathrm{O})$ & $17.81,18.27^{\mathrm{g}}$ \\
\hline Cf-12 & Cf-QILKYYNFT & $773.85^{\mathrm{b}}(1545.68)$ & $22.47,23.24^{\mathrm{g}}$ \\
\hline Cf-13 & Cf-PDRDHHKYR & $790.83^{b}(1579.66)$ & $18.66,19.20^{\mathrm{e}}$ \\
\hline Cf-14 & Cf-KRWLRYLRYP & $1807.91^{\mathrm{c}}(1806.90)$ & $18.71,19.63^{f}$ \\
\hline Cf-15 & Cf-F(2Nal)RRRRK & $1472.73^{c}(1471.73)$ & $18.32,18.99^{f}$ \\
\hline Cf-KB-752 & Cf-SRVTWYDFLMEDTKSR-OH & $2392.11^{\mathrm{C}}(2391.02)$ & $41.29^{d}$ \\
\hline Btn-GPM-1 & RWLRYLRYP-O2Oc-K(Biotin) & $1821.08^{\mathrm{c}}(1820.00)$ & $32.95^{\mathrm{d}}$ \\
\hline Btn-GPM-1C & $\mathrm{F}(2 \mathrm{Nal}) \mathrm{RRRRK}\left(\mathrm{PEG}_{4}-\right.$ Biotin)RWLRYLRYP & $2891.70^{\mathrm{C}}(2890.63)$ & $35 \cdot 93^{d}$ \\
\hline Btn-GPM-1d & cyc[RWLRYLRYP]F(2Nal)RRRRK(PEG ${ }_{4}$-Biotin) & $3107 \cdot 72^{\mathrm{c}}(3106.68)$ & $40.09^{d}$ \\
\hline Btn-GPM-15 & $\mathrm{F}(2 \mathrm{Nal}) \mathrm{RRRR}-\mathrm{O}_{2} \mathrm{Oc}-\mathrm{K}($ Biotin) & $1485.85^{\mathrm{c}}(1484.83)$ & $28.63^{d}$ \\
\hline
\end{tabular}

$\mathrm{M}=$ norleucine, as used in an earlier study ${ }^{37}$. All peptides were synthesized as acid amides unless otherwise stated. Mass peaks were detected as a) $[\mathrm{M}+\mathrm{H}]^{+}$and $\left.\mathrm{b}\right)[\mathrm{M}+2 \mathrm{H}]^{2+}$ with LC-ESI-MS and as c) $[\mathrm{M}+\mathrm{H}]^{+}$with MALDI-MS. For analytical RP-HPLC the following gradients were used: d) o - $60 \%$ eluent B in 60 min, e) $10-50 \%$ eluent B in 40 min, f) $20-50 \%$ eluent B in 30 min, g) $20-60 \%$ eluent B in 40 min. *All peptides were $>98 \%$ HPLC pure. 
Table S5. Validations of homology model from Swiss Model Software.

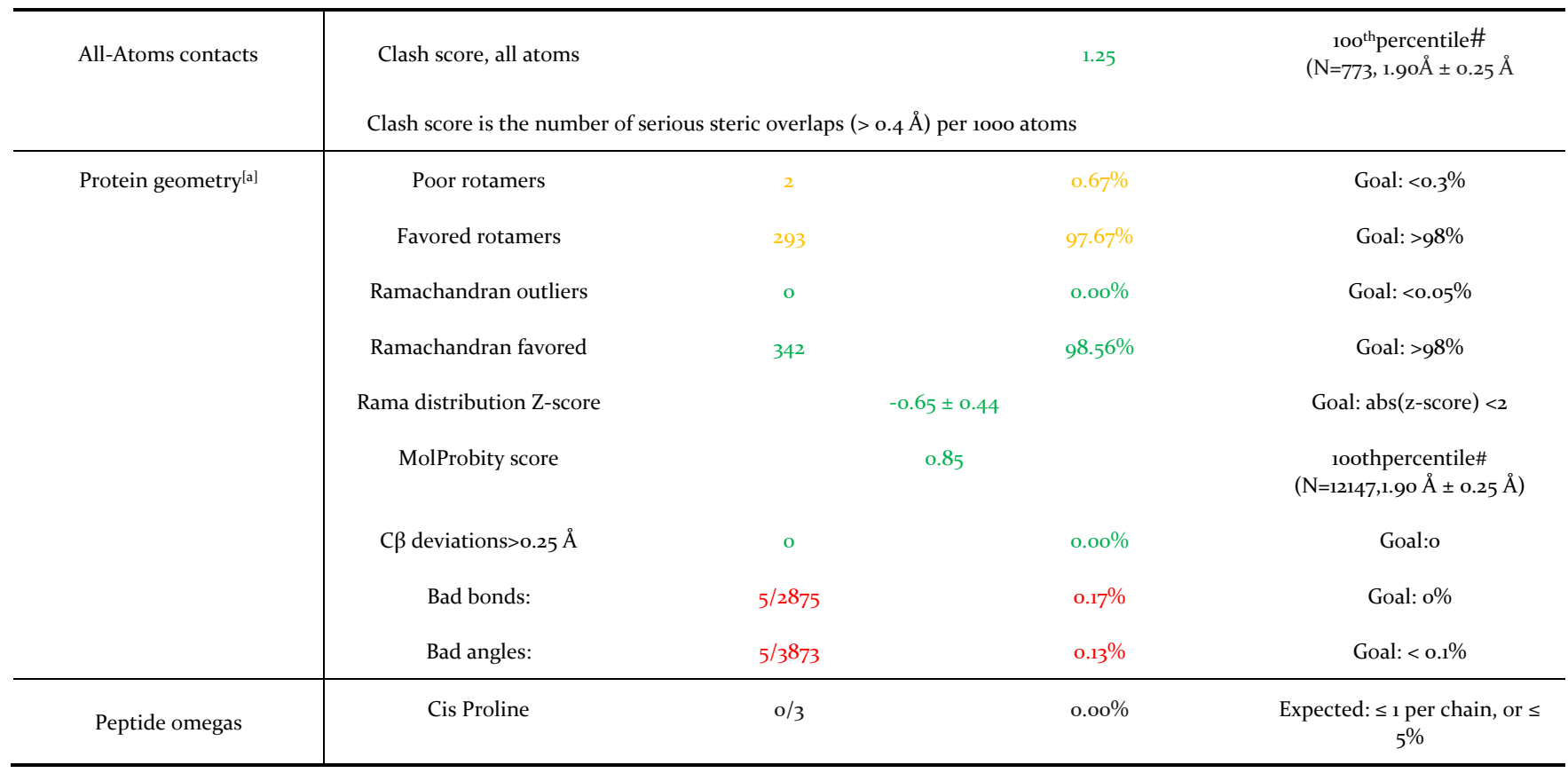

[a] The left column gives the raw count, right column gives the percentage, combine clash score, rotamer and Ramachandran evaluations of homology model. 10othpercentile\# is the best among structures of comparable resolutions, othpercentile is the worst. Color codes (Green: favored, yellow: moderate, red: unfavored).

Table S6. Homology model energy profile calculations.

\begin{tabular}{lcc}
\hline Total amino acids with high energy & 9 & percentage \\
$\begin{array}{l}\text { Total number of amino acids } \\
\text { Total number of non-local atomic }\end{array}$ & 349 & Total numbers of atoms \\
interactions & 45538 & Non-local normalized energy Z-score \\
$\begin{array}{l}\text { Total non-local energy of the protein } \\
\text { (E/KT units) }\end{array}$ & -2996 & \\
\hline
\end{tabular}

Table S7. Structural alignments of the GPM-1-derived peptides and peptide $\mathbf{1 5}$.

\begin{tabular}{|c|c|c|c|c|}
\hline peptide & GPM-1b & GPM-1c & GPM-1d & GPM-1 Y 5 A \\
\hline GPM-1 & $\begin{array}{c}3.44 \AA \AA \text { between } 9 \text { aligned } \\
\text { residues }\end{array}$ & $\begin{array}{c}2.94 \text { Å between } 9 \text { aligned } \\
\text { residues }\end{array}$ & 4.13 Å over 9 aligned residues & $\begin{array}{c}0.29 \AA ̊ \text { between } 4 \text { aligned } \\
\text { residues }\end{array}$ \\
\hline GPM-1b & - & n.d. & $\begin{array}{c}\text { 2.50 Å between } 9 \text { aligned } \\
\text { residues }\end{array}$ & n.d. \\
\hline 15 & n.d. & $\begin{array}{l}2.64 \AA \text { A between } 7 \text { aligned } \\
\text { residues }\end{array}$ & $\begin{array}{l}\text { 2.71 Å between } 7 \text { aligned } \\
\text { residues }\end{array}$ & n.d. \\
\hline
\end{tabular}

n.d.: not determined 
Table S8. Comparison between binding energy calculations predicted by VINA ${ }^{13}$ and PRODIGY ${ }^{17}$ for two best poses for each peptide in the Gai docked complexes.

\begin{tabular}{ccccc}
\hline peptide & $\begin{array}{c}\text { Binding Energy } \\
\text { Vina poser }\left(\mathrm{KJ} \mathrm{mol}^{-1}\right)\end{array}$ & $\begin{array}{c}\text { Binding Energy } \\
\text { Vina pose2 }\left(\mathrm{KJ} \mathrm{mol}^{-1}\right)\end{array}$ & $\begin{array}{c}\text { Binding Energy } \\
\text { PRODIGY poser }\left(\mathrm{KJ} \mathrm{mol}^{-1}\right)\end{array}$ & $\begin{array}{c}\text { Binding Energy } \\
\text { PRODIGY pose2 }\left(\mathrm{KJ} \mathrm{mol}^{-1}\right)\end{array}$ \\
\hline GPM-1 & -31.80 & -34.10 & -45.61 & -43.10 \\
GPM-1 Y 5A & -30.39 & -32.21 & -42.16 & -40.21 \\
GPM-1b & -24.69 & -33.18 & -37.66 & -38.49 \\
GPM-1C & -26.23 & -30.84 & -47.70 & -60.25 \\
GPM-1d & -27.15 & -29.33 & -43.51 & -46.44 \\
14 & -28.45 & -33.51 & -41.00 & -41.00 \\
15 & -31.13 & -34.90 & -38.07 & -36.82 \\
KB-752 & -26.61 & -30.08 & -39.75 & -40.58 \\
\hline
\end{tabular}

Table S9. Comparison between binding energy calculations predicted by VINA ${ }^{13}$ and PRODIGY ${ }^{17}$ for two best poses for each peptide in the $\mathrm{G} \alpha \mathrm{s}$ docked complexes.

\begin{tabular}{ccccc}
\hline peptide & $\begin{array}{c}\text { Binding Energy } \\
\text { Vina posel }\left(\mathrm{KJ} \mathrm{mol}^{-1}\right)\end{array}$ & $\begin{array}{c}\text { Binding Energy } \\
\text { Vina pose2 }\left(\mathrm{KJ} \mathrm{mol}^{-1}\right)\end{array}$ & $\begin{array}{c}\text { Binding Energy } \\
\text { PRODIGY posel }\left(\mathrm{KJ} \mathrm{mol}{ }^{-1}\right)\end{array}$ & $\begin{array}{c}\text { Binding Energy } \\
\text { PRODIGY pose2 }\left(\mathrm{KJ} \mathrm{mol}^{-1}\right)\end{array}$ \\
\hline GPM-1 & -27.48 & -26.25 & -43.11 & -41.40 \\
GPM-1 Y5A & -29.56 & -31.78 & -42.32 & -43.75 \\
GPM-1C & -36.41 & -37.66 & -48.63 & -49.65 \\
GPM-1d & -34.32 & -33.17 & -45.48 & -44.12 \\
\hline
\end{tabular}

Table S1o. Mean Backbone RMSD comparison table for MD simulation of Gai/s-bound and unbound peptides from their respective 50 ns MD simulation.

\begin{tabular}{|c|c|c|c|}
\hline \multirow[t]{2}{*}{ Peptide } & \multicolumn{3}{|c|}{ Mean backbone RMSD $(\AA)$} \\
\hline & RMSD unbound $(\AA)$ & RMSD Gai-bound ( $(̊)$ & RMSD Gas-bound ( () \\
\hline GPM-1 & $3.44 \pm 1.20$ & $3.42 \pm 0.98$ & $2.12 \pm 0.64$ \\
\hline GPM-1 Y5A & $3.66 \pm 1.75$ & $2.99 \pm 0.82$ & $2.73 \pm 1.47$ \\
\hline GPM-1b & $1.19 \pm 0.20$ & $3.11 \pm 0.82$ & n.d. \\
\hline GPM-1c & $6.23 \pm 1.50$ & $3.21 \pm 0.81$ & $2.71 \pm 1.11$ \\
\hline GPM-1d & $3.90 \pm 0.60$ & $2.79 \pm 0.66$ & $2.39 \pm 0.46$ \\
\hline 15 & $1.96 \pm 0.60$ & $2.13 \pm 0.42$ & n.d. \\
\hline
\end{tabular}

n.d.: not determined. 
Table S11. Mean MMPBSA binding energies calculated to quantify the interaction between each peptide and Gai as well as the interaction between GDP and Gai when a particular peptide is bound.

\begin{tabular}{|c|c|c|}
\hline \multirow[t]{2}{*}{ Peptide } & \multicolumn{2}{|c|}{ Mean MMPBSA energy $\left(\mathrm{kJ} \mathrm{mol}^{-1}\right)$} \\
\hline & Peptide-G $\alpha \mathrm{i}\left(\mathrm{kJ} \mathrm{mol}^{-1}\right)$ & GDP-G $\propto \mathrm{i}\left(\mathrm{kJ} \mathrm{mol}{ }^{-1}\right)$ \\
\hline GPM-1 & -300.23 & 286.27 \\
\hline GPM-1 Y $Y_{5}$ & -401.87 & 158.65 \\
\hline GPM-1b & -497.82 & 318.34 \\
\hline GPM-1c & 67.56 & -436.38 \\
\hline GPM-1d & 30.34 & -433.67 \\
\hline 15 & -512.17 & 309.67 \\
\hline N/A & N/A & -306.23 \\
\hline
\end{tabular}

The last row shows the binding energy of GDP on the Gai homology model. More positive values for binding energies indicate better binding.

Table S12. Mean MMPBSA binding energies calculated to quantify the interaction between each peptide and Gas as well as the interaction between GDP and Gas when a particular peptide is bound.

\begin{tabular}{|c|c|c|}
\hline \multirow[t]{2}{*}{ Peptide } & \multicolumn{2}{|c|}{ Mean MMPBSA energy $\left(\mathrm{kJ} \mathrm{mol}^{-1}\right)$} \\
\hline & Peptide-Gas $\left(\mathrm{kJ} \mathrm{mol}^{-1}\right)$ & GDP-G $\alpha \mathrm{s}\left(\mathrm{kJ} \mathrm{mol}^{-1}\right)$ \\
\hline GPM-1 & 110.53 & 166.73 \\
\hline GPM-1 $Y_{5} A$ & -413.45 & -198.12 \\
\hline GPM-1c & 288.24 & 332.78 \\
\hline GPM-1d & 192.74 & 246.87 \\
\hline N/A & N/A & -248.12 \\
\hline
\end{tabular}

The last row shows the binding energy of GDP to G $\alpha$. More positive values for binding energies indicate better binding. 


\section{Supporting Video Description}

Video S1: MD simulation of GPM-1 bound to G $\alpha$. The movie shows the recording of a 50 ns MD simulation trajectory of GPM-1 bound to Gai. GPM-1 is depicted in red while the structure of Gai is in gray cartoons. A VdW spheres representation of the bound GDP molecule is also displayed. Secondary structures are dynamically updated using the STRIDE algorithm 43 . 2000 frames from the raw trajectory were subjected to a smoothing factor of 5 to generate the movie.

Video S2: MD simulation of GPM-1b bound to Gai. The movie shows the recording of a 50 ns MD simulation trajectory of GPM-1b

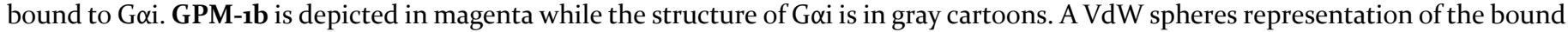
GDP molecule is also displayed. Secondary structures are dynamically updated using the STRIDE algorithm ${ }^{43}$. 20oo frames from the raw trajectory were subjected to a smoothing factor of 5 to generate the movie.

Video S3: MD simulation of GPM-1c bound to G $\alpha$ i. The movie shows the recording of a 50 ns MD simulation trajectory of GPM-1c

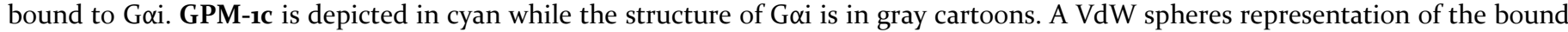
GDP molecule is also displayed. Secondary structures are dynamically updated using the STRIDE algorithm ${ }^{43}$. 200o frames from the raw trajectory were subjected to a smoothing factor of 5 to generate the movie. 


\section{References}

M. C. Sweeney, A.-S. Wavreille, J. Park, J. P. Butchar, S. Tridandapani, D. Pei, Biochemistry 2005, 44, 14932-14947.

M. C. Sweeney, D. Pei, J. Comb. Chem. 2003, 5, 218-222.

R. Aasland, C. Abrams, C. Ampe, L. J. Ball, M. T. Bedford, G. Cesareni, M. Gimona, J. H. Hurley, T. Jarchau, V. P. Lehto, et al., FEBS letters 2002, 513, 141-144.

B. Nubbemeyer, A. Pepanian, A. A. Paul George, D. Imhof, ChemMedChem 2021, 16, 1697-1716.

M. Moreno, E. Giralt, Toxins 2015, 7, 1126-1150.

6 N. A. Lambert, C. A. Johnston, S. D. Cappell, S. Kuravi, A. J. Kimple, F. S. Willard, D. P. Siderovski, Proc. Natl. Acad. Sci. U. S. A. 2010, 107, 7066-7071.

D. Goricanec, R. Stehle, P. Egloff, S. Grigoriu, A. Plückthun, G. Wagner, F. Hagn, Proc. Natl. Acad. Sci. U. S. A. 2016, 113, E3629-E3638.

8 M.-y. Shen, A. Sali, Protein Sci. 2006, 15, 2507-2524.

9 F. Melo, D. Devos, E. Depiereux, E. Feytmans, Proceedings. International Conference on Intelligent Systems for Molecular Biology 1997, 5 , 187-190.

$10 \quad$ E. Krieger, T. Darden, S. B. Nabuurs, A. Finkelstein, G. Vriend, Proteins 2004, 57, 678-683.

11 J. A. Maier, C. Martinez, K. Kasavajhala, L. Wickstrom, K. E. Hauser, C. Simmerling, J. Chem. Theory Comput. 2015, 11, 3696-3713.

12 E. M. Novoa, L. Ribas de Pouplana, X. Barril, M. Orozco, J. Chem. Theory Comput 2010, 6, 2547-2557.

13 O. Trott, A. J. Olson, J. Comput. Chem. 2010, 31, 455-461.

14 X. Liu, X. Xu, D. Hilger, P. Aschauer, J. K. S. Tiemann, Y. Du, H. Liu. K. Hirata, X. Sun, R. Guixa-Gonzalez, et al., Cell 2019, 177, 1243-1251.

15 A. Volkamer, D. Kuhn, T. Grombacher, F. Rippmann, M. Rarey, J. Chem. Inf. Model. 2012, 52, 360-372.

16 A. Volkamer, A. Griewel, T. Grombacher, M. Rarey, J. Chem. Inf. Model 2010, 50, 2041-2052.

17 A. Varshney, F. P. Brooks, W. V. Wright, IEEE Comput. Graphics and Applications 1994, 14, 19-25.

18 C. A. Johnston, J. K. Ramer, R. Blaesius, Z. Fredericks, V. J. Watts, D. P. Siderovski, FEBS Lett. 2005, 579, 5746-5750.

19 M. M. Bradford, Anal. Biochem. 1976, 72, 248-254.

20 D. Imhof, K. Wieligmann, K. Hampel, D. Nothmann, M. S. Zoda, D. Schmidt-Arras, M. Zacharias, F. D. Böhmer, S. Reissmann, J. Med. Chem. 2005, 48, 1528.

21 H. Ammer, R. Schulz, FEBS Lett. 2000, 485, 157-162.

22 H. Ammer, R. Schulz, Mol. Pharmacol. 1997, 52, 993-999.

23 J. K. Horton, R. C. Martin, S. Kalinka, A. Cushing, J. P. Kitcher, M. J. O'Sullivan, P. M. Baxendale, J. Immunol. Methods 1992, 155, 31-40.

24 R. Reher, T. Kühl, S. Annala, T. Benkel, D. Kaufmann, B. Nubbemeyer, J. P. Odhiambo, P. Heimer, C. A. Bäuml, S. Kehraus, M. Crüsemann, E. Kostenis, D. Tietze, G. M. König, D. Imhof, ChemMedChem 2018, 13, 1634-1643.

25 R. Schrage, A.-L. Schmitz, E. Gaffal, S. Annala, S. Kehraus, D. Wenzel, K. M. Büllesbach, T. Bald, A. Inoue, Y. Shinjo, et al., Nat. Commun. $2015,6,10156$

26 R. Schröder, N. Merten, J. M. Mathiesen, L. Martini, A. Kruljac-Letunic, F. Krop, A. Blaukat, Y. Fang, E. Tran, T. Ulven, et al., J. Biol. Chem. 2009, 284, 1324-1336.

27 E. W. K. Seemann, D. Wenzel, R. Schrage, J. Etscheid, T. Bödefeld, A. Bartol, M. Warnken, P. Sasse, J. Klöckner, U. Holzgabe, M. et al., J. Pharmacol. Ther. 2017, 360, 289-299.

28 J. Antony, K. Kellershohn, M. Mohr-Abdrä, A. Kebig, S. Prilla, M. Muth, E. Heller, T. Disingrini, C. Dallanoce, S. Bertoni, J. et al., FASEB J. 2009, 23, 442-450.

29 E. Krieger, G. Vriend, Bioinformatics 2014, 30, 2981-2982.

30 E. Krieger, K. Joo, J. Lee, J. Lee, S. Raman, J. Thompson, M. Tyka, D. Baker, K. Karplus, Proteins 2009, 77 Suppl 9, 114-122.

31 A. Jakalian, D. B. Jack, C. I. Bayly, J. Comput. Chem. 2002, 23, 1623-1641.

32 J. Wang, R. M. Wolf, J. W. Caldwell, P. A. Kollman, D. A. Case, J. Comput. Chem. 2004, 25, 1157-1174.

33 S. Peherstorfer, H. H. Brewitz, A. A. Paul George, A. Wißbrock, J. M. Adam, L. Schmitt, D. Imhof, Biochim. Biophys. Acta - General Subjects 2018, 1862, 1964-1972.

34 C. A. Bäuml, A. A. Paul George, T. Schmitz, P. Sommerfeld, M. Pietsch, L. Podsiadlowski, T. Steinmetzer, A. Biswas, D. Imhof, Eur. J. Med. Chem. 2020, 112474 .

35 A. A. Paul George, P. Heimer, E. Leipold, T. Schmitz, D. Kaufmann, D. Tietze, S. H. Heinemann, D. Imhof, Mar. Drugs $2019, \mathbf{1 7}, 390$.

36 N. Schneider, G. Lange, S. Hindle, R. Klein, M. Rarey, J. Comput. Aided Mol. Des. 2013, 27, 15-29.

37 T. Kühl, N. Sahoo, M. Nikolajski, B. Schlott, S. H. Heinemann, D. Imhof, Chembiochem. 2011, 12, 2846-2855.

38 N. A. Kalogriopoulos, S. D. Rees, T. Ngo, N. J. Kopcho, A. V. Ilatovskiy, N. Sun, E. A. Komives, G. Chang, P. Ghosh, I. Kufareva, Proc. Natl. Acad. Sci. U. S. A. 2019, 116, 16394-16403.

39 A. S. Konagurthu, J. C. Whisstock, P. J. Stuckey, A. M. Lesk, Proteins 2006, 64, 559-574

$40 \quad$ I. Reulecke, G. Lange, J. Albrecht, R. Klein, M. Rarey, ChemMedChem 2008, 3, 885-897.

41 F. Madeira, Y. M. Park, J. Lee, N. Buso, T. Gur, N. Madhusoodanan, P. Basutkar, A. R. N. Tivey, S. C. Potter, R. D. Finn, et al., Nucleic Acids Res.2019, 47, W636-W641.

42 C. A. Johnston, F. S. Willard, M. R. Jezyk, Z. Fredericks, E. T. Bodor, M. B. Jones, R. Blaesius, V. J. Watts, T. K. Harden, J. Sondeket al., Structure 2005, 13, 1069-1080.

43 D. Frishman, P. Argos, Proteins 1995, 23, 566-579. 